This item was submitted to Loughborough's Research Repository by the author.

Items in Figshare are protected by copyright, with all rights reserved, unless otherwise indicated.

\title{
Microbubble-enhanced DBD plasma reactor: Design, characterisation and modelling
}

PLEASE CITE THE PUBLISHED VERSION

https://doi.org/10.1016/j.cherd.2019.01.030

\section{PUBLISHER}

Elsevier () Institution of Chemical Engineers

\section{VERSION}

AM (Accepted Manuscript)

\section{PUBLISHER STATEMENT}

This work is made available according to the conditions of the Creative Commons Attribution-NonCommercialNoDerivatives 4.0 International (CC BY-NC-ND 4.0) licence. Full details of this licence are available at: https://creativecommons.org/licenses/by-nc-nd/4.0/

\section{LICENCE}

CC BY-NC-ND 4.0

\section{REPOSITORY RECORD}

Wright, Alexander R.P., Matteo Taglioli, Faraz Montazersadgh, Alex Shaw, Felipe Iza, and Hemaka Bandulasena. 2019. "Microbubble-enhanced DBD Plasma Reactor: Design, Characterisation and Modelling". figshare. https://hdl.handle.net/2134/36782. 


\title{
Microbubble-Enhanced DBD Plasma Reactor: Design, Characterisation and
}

\section{Modelling}

Alexander Wright ${ }^{\mathrm{a}, \mathrm{c}}$, Matteo Taglioli ${ }^{\mathrm{a}, \mathrm{b}, \mathrm{c}}$, Faraz Montazersadgh ${ }^{\mathrm{a}, \mathrm{c}}$, Alex Shaw ${ }^{\mathrm{c}}$, Felipe Iza ${ }^{\mathrm{c}}, \mathrm{H}_{\mathrm{C}}$ Hemaka

Bandulasena $^{\mathrm{a}^{*}}$

a Department of Chemical Engineering, Loughborough University, Loughborough, Leicestershire, LE11 3TU, United Kingdom

${ }^{\mathrm{b}}$ Department of Civil, Chemical, Environmental and Materials Engineering, University of Bologna 40136, Italy

${ }^{\mathrm{c}}$ Wolfson School of Mechanical, Electrical and Manufacturing Engineering, Loughborough University, Loughborough, Leicestershire, LE11 3TU, United Kingdom

Keywords

- $\quad$ Microbubbles

- $\quad$ Finite Element Method

- Ozone

- $\quad$ Airlift loop

- DBD plasma

\begin{abstract}
The emerging field of atmospheric pressure plasmas (APPs) for treatment of various solutions and suspensions has led to a variety of plasma reactors and power sources. This article reports on the design, characterisation and modelling of a novel plasma-microbubble reactor that forms a dielectric barrier discharge (DBD) at the gas-liquid interface to facilitate the transfer of short-lived highly reactive species from the gas plasma into the liquid phase. The use of microbubbles enabled efficient dispersion of long-lived reactive species in the liquid and UVC-induced oxidation reactions are triggered by the plasma radiation at the gas-liquid interface. A numerical model was developed to understand the dynamics of the reactor, and the model was validated using experimental measurements. Fluid velocities in the riser region of the reactor were found to be an order of magnitude higher for smaller bubbles ( $\sim 500 \mu \mathrm{m}$ diameter $)$ than for larger bubbles ( $2500 \mu \mathrm{m}$ diameter $)$; hence provided well-mixed conditions for treatment. In addition to other reactive oxygen species (ROS) and reactive nitrogen species (RNS),
\end{abstract}


a dissolved ozone concentration of $3 \mu \mathrm{M}$ was recoded after a 15-minute operation of the reactor, demonstrating the suitability of this design for various applications.

\section{Nomenclature}

\begin{tabular}{|c|c|c|c|c|c|}
\hline Term & Definition & & Term & Definition & Unit \\
\hline$\varnothing$ & Liquid phase fraction & - & $D_{i}$ & $\begin{array}{l}\text { Diffusion Coefficient of } \\
\text { species } i\end{array}$ & $\mathrm{~m}^{2} \mathrm{~s}^{-1}$ \\
\hline$\rho$ & Liquid density & $\mathrm{Kg} \mathrm{m}^{-3}$ & $R_{i}$ & Reaction rate of species $i$ & $\begin{array}{l}1^{\text {st }} \text { order } \mathrm{s}^{-1} \\
2^{\text {nd }} \text { order } \mathrm{m}^{3} \mathrm{~s}^{-1} \mathrm{~mol}^{-1} \\
3^{\text {rd }} \text { order } \mathrm{m}^{6} \mathrm{~s}^{-1} \mathrm{~mol}^{-2} \\
4^{\text {th }} \text { order } \mathrm{m}^{9} \mathrm{~s}^{-1} \mathrm{~mol}^{-3}\end{array}$ \\
\hline$U$ & Velocity magnitude & $\mathrm{m} \mathrm{s}^{-1}$ & $m_{g l}$ & Mass transfer & $\mathrm{Kg} \mathrm{m}^{-3} \mathrm{~s}^{-1}$ \\
\hline$t$ & Time & $\mathrm{s}$ & $d_{b}$ & Bubble size & $\mathrm{m}$ \\
\hline$p$ & Pressure & $\mathrm{Pa}$ & $G r$ & Grashof number & - \\
\hline$C_{l}$ & $\begin{array}{l}\text { Concentration of } \\
\text { species } i \text { in the liquid }\end{array}$ & $\mathrm{mol} \mathrm{m}^{3}$ & $S c$ & Schmidt number & - \\
\hline$C_{g}$ & $\begin{array}{l}\text { Concentration of } \\
\text { species } i \text { in the gas }\end{array}$ & $\mathrm{mol} \mathrm{m}^{3}$ & $S h$ & Sherwood number & - \\
\hline$T$ & Temperature & $\mathrm{K}$ & $K_{L} a$ & Rate coefficient & $\mathrm{m} \mathrm{s}^{-1}$ \\
\hline$g$ & $\begin{array}{l}\text { Gravitational } \\
\text { acceleration }\end{array}$ & $\mathrm{m} \mathrm{s}^{-2}$ & $\mu_{T}$ & Turbulent velocity & $\mathrm{m}^{2} \mathrm{~s}^{-1}$ \\
\hline$C_{i}$ & $\begin{array}{l}\text { Concentration of } \\
\text { species } i\end{array}$ & $\mathrm{~mol} \mathrm{~m}^{3}$ & $H$ & Henry's constant & $\mathrm{Pa} \mathrm{m}^{3} \mathrm{~mol}^{-1}$ \\
\hline$\overline{\overline{a_{l}^{V}}}$ & Interfacial area & $\mathrm{m}^{-1}$ & $\mu_{l}$ & Dynamic liquid velocity & Pa s \\
\hline V & Volume & $\mathrm{m}^{3}$ & $M_{w}$ & Molecular weight & $\mathrm{g} \mathrm{mol}^{-1}$ \\
\hline
\end{tabular}

\subsection{Introduction}

Ozone has been established as an excellent oxidising agent and used on industrial scale for water treatment worldwide (Loeb et al., 2012). Its high oxidation potential of $2.07 \mathrm{~V}$ is superior to that of chlorine (1.36 V), and 
the ability to produce ozone in-situ on-demand makes it an attractive alternative. Although ozone is often the focal oxidative species produced from an atmospheric pressure plasma (APP), other highly reactive species are also generated in the process, including hydrogen peroxide, superoxide, atomic oxygen, hydroxyl radicals $(\cdot \mathrm{OH})$, perhydroxyl radicals and singlet oxygen, which are collectively known as reactive oxygen species (ROS). If nitrogen is present in the feed gas, peroxynitrites and nitrogen-based acids such as $\mathrm{HNO}_{3}, \mathrm{HNO}_{2}$ and $\mathrm{NO}^{-}$are also produced. These species are collectively known as reactive nitrogen species (RNS). These reactive species often interact synergistically, increasing the effectiveness of the oxidation process.

The production of $\cdot \mathrm{OH}$ in these systems categorises APP as an advanced oxidation process (AOP). $\cdot \mathrm{OH}$ are generated both directly in the gas plasma and in subsequent reactions in the liquid phase. For instance, dissolved ozone and hydrogen peroxide can react to generate $\cdot \mathrm{OH}$ and hydrogen peroxide can be photodissociated in the presence of the plasma UV light. This combined approach has been proven advantageous as $\cdot \mathrm{OH}$ has a greater oxidation potential and it is more efficient than ozone alone in removing chemical pollutants such as cyanide, arsenide and ammonia (Von Gunten, 2003). Additionally, the combined effect of ROS and RNS has been shown to be highly effective in disinfecting water born microorganisms, such as E. coli and cryptosporidium (Hayes et al., 2013; Kim et al., 2013). It is anticipated that a scalable and highly efficient APP reactor would be beneficial to many potential industrial applications such as water treatment (Loeb et al., 2012), pretreatment of lignocellulosic biomass (Wright et al., 2018), seed treatment (Sivachandiran and Khacef, 2017), food industry (Shaw et al., 2015) and chemical processing (Rumbach and Go, 2017). These emerging wide-ranging applications have led to various designs of APP reactors. In most cases, however, the research focus has been in proof-ofprinciple studies and little attention has been given to the efficiency of the delivery of reactive species from plasma to the liquid and the scalability of the designs.

Highly-reactive species generated from an APP that have a very short half-life in the order of few nanoseconds to few milliseconds, such as $\cdot \mathrm{OH}$ and superoxide are very effective, but efficient delivery of these species to a liquid target is challenging. Therefore, it is important to consider not only the creation of these reactive species but also their efficient delivery into a target suspended in liquid when designing APP systems. Microbubbles have a large surface to volume ratio which can facilitate this delivery and induce convection currents that aid mixing of dissolved species within a reactor. This can lead to high mass transfer rates (Wei et al., 2017; Wright et al., 2018). Microbubbles generated by fluidic oscillation, an energy efficient and scalable technology, has been explored for non-plasma applications such as wastewater aeration (Rehman et al., 2015), bioreactors, aqua culture and 
separation (AL-Mashhadani et al., 2015; Ying et al., 2013a). Conventional aeration systems typically produce bubbles sizes of the order of 1-3 mm from sintered ceramic or rubber aerators. However, microbubbles generated from perforated through-hole membranes such as nylon, stainless steel and nickel can produce smaller bubbles $(\sim 200 \mu \mathrm{m}$ to $800 \mu \mathrm{m})$ as these membranes reduce bubble coalescence due to a uniform distribution of pores (Hanotu et al., 2017). Use of microbubbles to disperse species produced by APP would be an effective approach in improving the efficiency of existing reactors.

There are hundreds of reactions that occur within a plasma as the feed gas is excited, dissociated and ionised to form free electrons, excited atoms/molecules and ions which then participate in a series of reactions to form a complex combination of ROS and RNS. In addition to these reactive species, relaxation of exited states emits UV radiation which can further contribute to the efficacy of the treatment. To understand the gas chemistry of these discharges and to analyse their complex reaction schemes, plasma scientists have developed different computational techniques. For example, Sakiyama et al., 2012 developed an air plasma chemistry model that included over 50 species and 600 elementary reactions. Further work has been reported in modelling the interaction of these type of plasma discharges and its effluent with multiple, media including solid surface (Sigeneger et al., 2016), tissue cultures (Tian and Kushner, 2014) and liquids (Liu et al., 2015). Henry's law is often used in these models to account for transport of reactive species from plasma or gas phase to the liquid phase. The Henry's constant is a dimensionless ratio between the concentration in the aqueous phase and that in the gas phase:

$$
k_{H}^{c c}=\frac{c_{l}}{c_{g}}
$$

However, Henry's law stated in equation (1) is only suitable for equilibrium systems at steady state. For dynamic systems, such as bubbly flow reactors where spatial and temporal changes to concentration can be expected, the two-film theory should be applied.

$$
m_{g l}=K_{l}\left(C^{*}-C_{l}\right) \times M_{w} \times \overline{a_{l}^{V}}
$$

where $C^{*}$ is the equilibrium concentration $\left(\frac{P}{H}\right)_{i}$ and $\overline{a_{l}^{V}}$ is the interfacial area that depends on the bubble size and bubble density. Whilst well established in many fields, including water ozonation (Lucas et al., 2009), the use of two film theory by the APP community is very limited. Some lessons could be learnt from the detailed models that have been developed in other fields to describe mass transfer from bubbles to liquid, taking into account 
bubble shrinkage and gas composition inside the bubbles (Worden and Bredwell, 1998) as well as variation of surface tension and shell elasticity (Dalvi and Joshi, 2015).

Due to the myriad of emerging applications of APPs, large variations in reactor designs can be found in the literature. These reactor configurations may be highly specific for a particular application, such as a plasma jet for localised biomedical use. Therefore, designs and innovative approaches that improve efficiency of such processes is highly sought. Broadly, there are several configurations to bring a plasma in contact with a bulk target liquid: from above the liquid surface, within the liquid, from the side of a falling film and from below (Bruggeman et al., 2016). For some applications, droplets have also been considered (Multanen et al., 2016). Most studies reported so far have used the discharge above or within a liquid volume to treat the liquid. When the plasma discharge is generated above a liquid, most of the reactive species remain in the gas phase as the mass transfer process depends on the limited gas-liquid interface. Whilst convection and electro-hydrodynamic effects can be used to enhance the delivery of species into the liquid (Taglioli et al., 2016), the limited surface area of the gas-liquid interface ultimately limits the transport. Whilst this limitation can be alleviated by generating the discharge within the liquid, doing so can be challenging due to high voltage and high frequency required and the need for specialised power supplies (Pongrác et al., 2018). Here we explore the formation of the discharge in a plenum chamber under the liquid volume and disperse the plasma effluent as bubbles through the liquid (Wright et al., 2018; Zhou et al., 2016).

The focus of this study is to design, characterise and model a scalable reactor that brings a DBD plasma to the gas-liquid interface to facilitate transfer of short-lived reactive species and then disperse the long-lived plasma products efficiently using microbubbles. Additionally, if UV radiation emitted by the plasma discharge is also available at the 'skin' of the microbubbles during bubble formation, that would enable further reactions to breakdown dissolved species such as peroxide and ozone to form $\cdot \mathrm{OH}$. Liquid circulation and mixing of dissolved species within the reactor is promoted by integrating a draft tube to induce air-lift effect. The suitability of this design for various applications such as water treatment or lignocellulosic biomass pretreatment will depend on the cocktail of reactive species generated and their concentrations within the liquid phase; hence the reactor performance will be evaluated for various operating regimes. A numerical model is developed to understand the dynamic nature of the reactor and to predict outputs for potential applications. 


\subsection{Reactor Design and the Experimental Rig}

\subsection{Plasma-microbubble Reactor Design}

A schematic diagram of the plasma-microbubble reactor developed in this study is shown in Figure 1. The reactor has two main sections with different functionalities. The lower section of the reactor underneath the membrane is the plenum chamber with a plasma module where a DBD discharge is ignited. The upper section of the reactor is where target liquid is held, and bubbles are introduced to transfer reactive species produced by the plasma. The plasma module consists of 19 high voltage (HV) electrodes wired in parallel to a stainless-steel ring which is connected to the high voltage output of the power supply. Each HV electrode assembly consists of a cylindrical stainless-steel rod with a hemispherical cap at the top end encased in a quartz crucible. The dimensions of the stainless-steel rods (length $=90 \mathrm{~mm}$, diameter $=7 \mathrm{~mm}$ ) and the quartz crucibles $($ length= $=80 \mathrm{~mm}$, inner diameter $=$ $7 \mathrm{~mm}$ ) were selected to give a tight fit between them. The quartz crucibles serve as the dielectric barrier required for the DBD plasma and have a wall thickness of $1.5 \mathrm{~mm}$ necessary to form a uniform discharge. HV electrodes were held within the crucibles by a PTFE plug. The array of 19 HV electrode assemblies are separated $14 \mathrm{~mm}$ apart and held in place with two compressed PTFE mounts. The lower mount provides a gas tight fit around the crucibles while the upper mount supports the crucibles in square holes. Feed gas enters this chamber radially and rises through the gaps between the square holes and the circular crucibles in the top PTFE mount into the plenum chamber. The height and the internal diameter of the plenum chamber are $30 \mathrm{~mm}$ and $80 \mathrm{~mm}$ respectively providing a volume of $150 \mathrm{~cm}^{3}$. The gap between the quartz crucible tips and the metallic porous membrane electrode is set approximately $1 \mathrm{~mm}$. A larger gap would require higher voltage to ignite the plasma and it will result in a hotter discharge, which can be detrimental to ozone generation efficiency. Smaller gaps would reduce the plasma volume and hence potentially the overall ROS production. The porous membrane used in this reactor serves two purposes: firstly, it serves as the ground electrode for the plasma generation and secondly, as the bubble forming sparger for the dispersion of plasma products. Two different membranes were used in this study to achieve different bubble sizes. The first one is a perforated nickel membrane (Micropore Ltd) with a pore size of $20 \mu \mathrm{m}$ and a pitch of $180 \mu \mathrm{m}$, and the second one is a woven stainless-steel mesh (Plastok Ltd, UK) with an aperture of $35 \mu \mathrm{m}$ with a wire diameter of $30 \mu \mathrm{m}$. These membranes were soldered to a copper support ring housed within the aluminium frame and electrically grounded. 


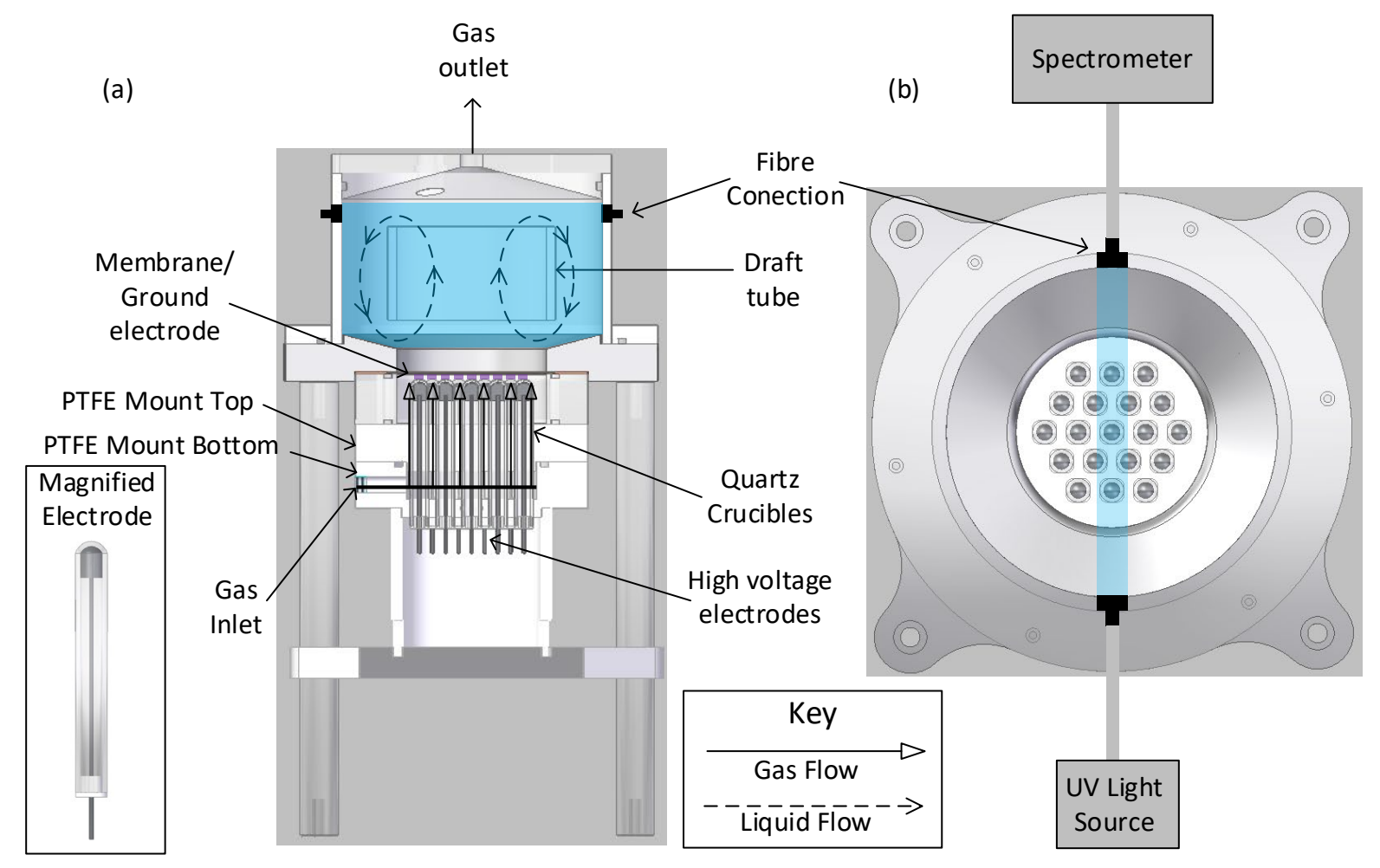

Figure 1: A schematic diagram of the plasma-microbubble reactor design (a) cross-sectional front elevation (b) plan view.

The plan view in figure 1(b) shows the electrode configuration and the fibre optic arrangement for dissolved ozone measurements. The upper section of the reactor, i.e. the reaction tank, has a total usable capacity of $1 \mathrm{~L}$ and the height and the diameter of this tank are $90 \mathrm{~mm}$ and $140 \mathrm{~mm}$, respectively. To ensure good mixing within the reaction tank, a draft tube with a height of $50 \mathrm{~mm}$ and an internal diameter of $80 \mathrm{~mm}$ was installed. Dimensions and placement of the draft tube were calculated according to Ying et al., 2013. The air-lift loop design allows the reactor to operate without mechanical stirring as natural convection currents were induced by buoyancy-driven bubbly flow. This approach has the added advantage of simplicity as it does not require moving parts and it is more economical than other external mixing technologies. The reaction tank is hermetically sealed at the top with a lid where the exhaust and characterization probes are connected.

\subsection{Resonant Plasma Power Source}

To generate the plasma discharge, a full-bridge resonant power supply was designed and built in-house. An outline of the controls of the power supply unit is shown in Figure 2. The mains voltage is first stepped down to 60 volts with a toroidal transformer before being rectified to DC. The DC output is then fed into the full bridge circuitry which forms a high-frequency $(1-100 \mathrm{kHz})$ square waveform. The square waveform is applied to a partial core 
resonant transformer which filters out high order harmonics and increases the voltage up to $50 \mathrm{kV}$. Due to the topology of the power supply, the frequency and voltage are linked; hence a change in the frequency will produce a different output voltage. The power supply can be operated with a continuous or modulated AC output. When modulated, the ratio of the on-time to the off-time can be varied, thereby adjusting the duty cycle.

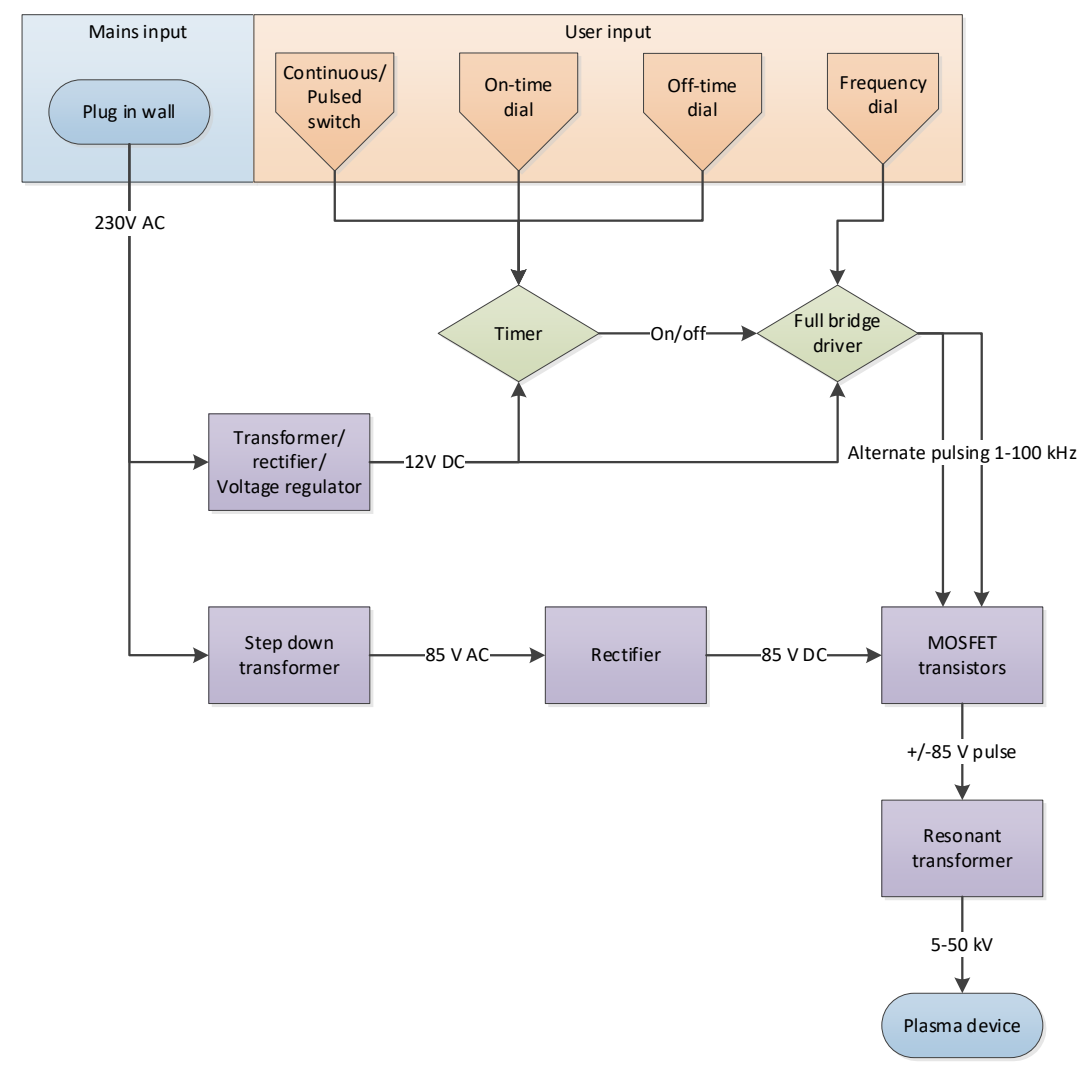

Figure 2: Outline topology of the full-bridge resonant power supply 


\subsection{Characterisation of the Power Source}

To ensure that the plasma discharge is the same for both membranes, the average power delivered to the plasma was kept constant. The average power was determined using charge vs voltage (Q-V) Lissajous diagrams (Manley, 1943). The output voltage of the power supply was measured with a high-voltage probe (Tektronix P6015) connected to an oscilloscope (Tektronix, TDS 2012 B) and the voltage across the measuring capacitor on the ground electrode was measured using a voltage probe (Pico, TA150). This experiment was repeated 6 times for each membrane and 128 waveforms were recorded for each run. The recorded waveforms were then exported to a computer and analysed using Matlab ${ }^{\mathrm{TM}}$. Measurement probes have different intrinsic delays due to the differences in parasitic capacitances and inductances of the cables. Since power calculations require signals measured simultaneously, data recorded by the oscilloscope was time-shifted to account for the probe delays. Average power consumption was then calculated from these time adjusted measurements. For both membranes, the input power to the discharge was adjusted by changing the operation frequency between 23 and $38 \mathrm{kHz}$.

\subsection{Bubble Generation and Analysis}

To generate bubbles of two different sizes, a nickel or a stainless-steel membrane was installed in the reactor and synthetic air was supplied at 0.75 SLPM via a mass flow controller (MKS, PR4000B). The resultant bubble size distribution was measured using a high-speed camera (Photon Fastcam, M2.1) coupled with a long-distance lens (Infinity, KC). To provide illumination for high-speed video recordings, a $1000 \mathrm{~W}$ halogen light source and a diffuser sheet was placed behind the reactor directly in line with the camera. Every $1 / 100^{\text {th }}$ frame was stored in the computer for analysis to ensure that there were no repeated measurements of the same bubble with a 30 seconds time frame. These experiments were repeated 10 times to collect sufficient number of images for analysis (approximately 10,000). The resultant bubble size distributions were determined using ImageJ.

\subsection{Optical Emission Spectroscopy}

To confirm that the plasma discharge produced with both membranes have the same characteristics and that any difference observed in the liquid can be attributed to the bubble size, optical emission spectroscopy (OES) was used to collect radiation emitted from the discharge. The plasma emission spectra were collected using a collimating lens, an Ocean Optics QR400-7-UV/VIS optical fibre and an Andor SR-303i-A Czerny-Tuner spectrograph. The entrance slit and the holographic grating were set at $10 \mu \mathrm{m}$ and $24001 / \mathrm{mm}$ respectively, and an ICCD camera paired to the monochromator was used as the detector. The camera exposure time was set at 100 ms, and 1000 acquisitions were performed for each membrane. These experiments were repeated five times. All 
the measured spectra were calibrated for wavelength and intensity by means of an Ocean Optics HG-1 MercuryArgon lamp and an Ocean Optics DH-2000-BAL Deuterium-Halogen light source respectively. The plasma temperature was inferred from the rotational temperature of nitrogen molecules (Bruggeman et al., 2014; Iza and Hopwood, 2004) and in particular the experimental spectra of the nitrogen second positive system $(\mathrm{C} 3 \Pi \mathrm{u}-\mathrm{B} 3 \Pi \mathrm{g})$ was compared to synthetic spectra generated using SPECAIR (Laux, 2002).

\subsection{Fourier Transform Infrared (FTIR) Spectroscopy}

To determine the concentrations of RNS species produced by the DBD plasma discharge, the exhaust from the reactor operated with dry air (without liquid in the reaction tank) was fed into a variable path-length gas cell (Pike Technologies Ltd.) seated within an FTIR spectrometer (4700, Jasco Ltd.). Concentration of each species was determined using Beer-Lambert law at the following absorption wavenumbers: $\mathrm{N}_{2} \mathrm{O}$ at $2240 \mathrm{~cm}^{-1}, \mathrm{~N}_{2} \mathrm{O}_{5}$ at 750 $\mathrm{cm}^{-1}, \mathrm{HNO}_{3}$ at $890 \mathrm{~cm}^{-1}$, and $\mathrm{NO}_{2}$ at $1580 \mathrm{~cm}^{-1}$ (Fitzsimmons et al., 1999).

\subsection{Ozone Measurements}

The concentration of ozone in both the gas and the liquid phase was measured using the set up shown in Figure 1. UV light emitted from a LED light source (LLS-255, Ocean Optics Ltd) was directed towards a collimating lens using optical fibres. Transmitted light was collected at $180^{\circ}$ opposite to the first lens using a spectrometer (HR2000+, Ocean Optics Ltd). By measuring the transmitted light intensity at $254 \mathrm{~nm}$ and using the Beer-Lambert law, the ozone concentration was inferred. For the gas measurements, experiments were repeated 5 times and a cross-sectional area of $1.12 \cdot 10^{-17} \mathrm{~cm}^{2}$ was used in the calculations (Grebenshchikov et al., 2007). For the liquid measurements, an absorption coefficient of $3300 \mathrm{M}^{-1} \mathrm{~cm}^{-1}$ was used in the calculations (Koh et al., 2001) with data obtained from experiments replicated in triplicate.

\subsection{Numerical Model}

The main purpose of the numerical model was to investigate the dynamic nature of the reactor, i.e. spatial and temporal evolution of reactive species as this will determine the reactor's efficiency and effectiveness for a given application. Additionally, the effect of changing the bubble size on the reactor's performance was also investigated. A chemical reaction scheme based on the work of Liu et al., 2015 was used to study the transfer of ten key longlived ROS and RNS from the gas plasma into the liquid. Within the liquid phase, these species react with each other to produce further 32 species. In total, 107 of the 109 reactions from Liu's reaction scheme were incorporated in the model as those involving the short-lived specie singlet oxygen could not be accurately determined in the 
gas phase. Table 1 lists all the reactive species modelled along with their diffusion coefficients and their Henry's law constants.

Table 1: A list of the reactive species in the model with their diffusion coefficients in water and the Henry's law constant at $19^{\circ} \mathrm{C}$. Diffusion coefficients and Henry's law constants were taken from Liu et al., 2015 and Sander, 1999 , respectively.

\begin{tabular}{|c|c|c|}
\hline Reactive Species & $\begin{array}{c}\text { Diffusion } \\
\text { Coefficient }\left(\mathrm{m}^{2} \mathrm{~s}^{-1}\right)\end{array}$ & $\begin{array}{l}\text { Henry's Constant } \\
\left(\text { Pa m}^{3} \mathrm{~mol}^{-1}\right)\end{array}$ \\
\hline $\mathrm{NO}_{2}$ & $1.85 \times 10^{-9}$ & $4.4694 \times 10^{-4}$ \\
\hline $\mathrm{NO}_{3}$ & $1 \times 10^{-9}$ & $3.8517 \times 10^{-4}$ \\
\hline $\mathrm{N}_{2} \mathrm{O}_{5}$ & $1 \times 10^{-9}$ & $2.620 \times 10^{-2}$ \\
\hline $\mathrm{HNO}_{2}$ & $1.85 \times 10^{-9}$ & $6.7332 \times 10^{-1}$ \\
\hline $\mathrm{HNO}_{3}$ & $2.6 \times 10^{-9}$ & $3.776 \times 10^{3}$ \\
\hline $\mathbf{O}_{3}$ & $1.75 \times 10^{-9}$ & $1.3069 \times 10^{-4}$ \\
\hline $\mathrm{H}_{2} \mathrm{O}_{2}$ & $1 \times 10^{-9}$ & $1.1606 \times 10^{3}$ \\
\hline $\mathbf{N}_{2} \mathbf{O}$ & $2.1 \times 10^{-9}$ & $2.226 \times 10^{-1}$ \\
\hline $\mathrm{O}_{2}$ & $2 \times 10^{-9}$ & $1.4228 \times 10^{-5}$ \\
\hline $\mathbf{N}_{2}$ & $1.88 \times 10^{-9}$ & $2.7158 \times 10^{-3}$ \\
\hline $\mathrm{H}_{2} \mathrm{O}$ & $1 \times 10^{-9}$ & - \\
\hline $\mathrm{HO}_{2}$ & $1 \times 10^{-9}$ & - \\
\hline $\mathrm{HO}_{2}^{-}$ & $1 \times 10^{-9}$ & - \\
\hline $\mathrm{HO}_{3}$ & $1 \times 10^{-9}$ & - \\
\hline $\mathbf{H}^{+}$ & $9.312 \times 10^{-9}$ & - \\
\hline $\mathbf{N}_{2} \mathrm{O}_{3}$ & $1 \times 10^{-9}$ & - \\
\hline $\mathrm{N}_{2} \mathrm{O}_{4}$ & $1 \times 10^{-9}$ & - \\
\hline NO & $2.21 \times 10^{-9}$ & - \\
\hline $\mathrm{NO}_{2}^{-}$ & $1.85 \times 10^{-9}$ & - \\
\hline $\mathrm{NO}_{3}{ }^{-}$ & $1.9 \times 10^{-9}$ & - \\
\hline $\mathbf{O}_{2}^{-}$ & $2 \times 10^{-9}$ & - \\
\hline$\cdot \mathbf{O H}$ & $2 \times 10^{-9}$ & - \\
\hline $\mathrm{OH}^{-}$ & $5.26 \times 10^{-9}$ & - \\
\hline $\mathbf{O}^{-}$ & $2 \times 10^{-9}$ & - \\
\hline -ONOOH & $2.6 \times 10^{-9}$ & - \\
\hline $\mathbf{H}_{2}$ & $4.5 \times 10^{-9}$ & - \\
\hline ONOOH & $2.6 \times 10^{-9}$ & - \\
\hline $\mathbf{O}_{3}^{-}$ & $1.75 \times 10^{-9}$ & - \\
\hline $\mathrm{O}_{2} \mathrm{NOOH}$ & $1 \times 10^{-9}$ & - \\
\hline $\mathrm{O}_{2} \mathrm{NOO}^{-}$ & $1 \times 10^{-9}$ & - \\
\hline
\end{tabular}




\begin{tabular}{|l|c|c|}
\hline $\mathbf{O}$ & $2 \times 10^{-9}$ & - \\
\hline $\mathbf{H}$ & $8 \times 10^{-9}$ & - \\
\hline
\end{tabular}

\subsection{Momentum balance}

The gas density was assumed to be negligible compared to that of the liquid, and therefore both phases in the bubbly flow were assumed to share the same pressure field. The bulk liquid and the gas phase were treated as interpenetrating media where the bubbles are uniformly distributed within the liquid phase with equal diameters. The liquid phase momentum balance is described by the Navier-Stokes equation (Al-mashhadani et al., 2012):

$$
\emptyset_{l} \rho_{l} \frac{\partial \boldsymbol{u}_{l}}{\partial t}+\emptyset_{l} \rho_{l}\left(\boldsymbol{u}_{l} \cdot \nabla\right) \boldsymbol{u}_{l}=\nabla \cdot\left[-p I+\emptyset_{l}\left(\mu_{l}+\mu_{T}\right)\left(\nabla \boldsymbol{u}_{l}+\left(\nabla \boldsymbol{u}_{l}\right)^{T}\right)\right]+\emptyset_{l} \rho_{l} \boldsymbol{g}
$$

The gas fraction is typically less than $10 \%$ by volume; hence both fluids can be assumed nearly incompressible. The continuity equation can be written as:

$$
\nabla \cdot \boldsymbol{u}_{l}=0
$$

At the porous membrane surface, a constant gas flux boundary condition was set, which corresponds to a net flow of 0.75 SLPM. The uppermost boundary, i.e. the free surface at the top, was set as the outlet to allow gas to exit the reactor with no constraints. The reaming walls of the reactor and the internal draft tube surfaces were set as no-slip boundaries.

\subsection{Mass balance}

The model assumes that only the long-lived species are transported by the bubbles from the plasma discharge to the liquid. Short-lived species produced within the plasma, such as $\cdot \mathrm{OH}$ and atomic oxygen are not considered in the simulation. Their effective diffusion lengths (EDL) are of the order of few nanometres (Liu et al., 2015) and hence these species are only available at the gas-liquid interface. Nonetheless, some of these short-lived species are also produced within the bulk liquid as a result of reactions between dissolved long-lived species. The initial gas composition of the bubbles was atmospheric air $\left(\mathrm{N}_{2}\right.$ and $\left.\mathrm{O}_{2}\right)$ with an admixture of long-lived reactive species set to match the concentration measured in the device when the reactor is run without liquid.

To model mass transfer of the reactive species from gas to liquid, the two-film theory was used (equation (2)). The mass transfer coefficient $\left(K_{l}\right)$ for a swarm of bubbles is estimated from an empirical correlation (equation (5)) according to Calderbank and Moo-Young, 1995.

$$
S h=K_{l} \frac{d_{b}}{D_{i}}=X \times G r^{\frac{1}{3}} \times S c^{Y}
$$


According to Calderbank and Moo-Young, 1995, for a bubble size of $2500 \mu \mathrm{m}, \mathrm{X}$ is 0.42 and $\mathrm{Y}$ is $1 / 2$, and for bubble size of $550 \mu \mathrm{m}, \mathrm{X}$ is 0.31 and $\mathrm{Y}$ is $1 / 3$. The Grashof number (6) and Schmidt number (7) are given by

$$
\begin{gathered}
G r=d_{b}{ }^{3} \times \rho_{l} \times g \times \frac{\rho_{l}-\rho_{g}}{\mu_{l}^{2}} \\
S c=\frac{\mu_{l}}{\rho_{l} \times D_{i}}
\end{gathered}
$$

Transport of species $i$ reacting with species $j$ with Fickian diffusion is described by:

$$
\frac{\partial c_{i}}{\partial t}+\nabla \cdot\left(-D_{i} \nabla c_{i}\right)+\boldsymbol{u} \cdot \nabla c_{i}=\sum_{j} R_{i j}+\left(\frac{m_{g l}}{M_{w}}\right)_{i}
$$

The initial concentrations of $\mathrm{H}^{+}$and $\mathrm{OH}^{-}$in the liquid were set as $1 \times 10^{-4} \mathrm{~mol} \mathrm{~m}^{-3}$ (i.e. $\mathrm{pH}=7$ ) and for all remaining ions $1 \times 10^{-19} \mathrm{~mol} \mathrm{~m}^{-3}$ to aid convergence. The reaction rates in the liquid are a function of the local liquid temperature. However, given the well-mixed conditions of the reactor and for simplicity, the liquid temperature was assumed to be constant throughout the entire reactor and fixed to $292 \mathrm{~K}$. This assumption is reasonable as only a $2 \mathrm{~K}$ difference in liquid temperature was observed over a 15-minute operation.

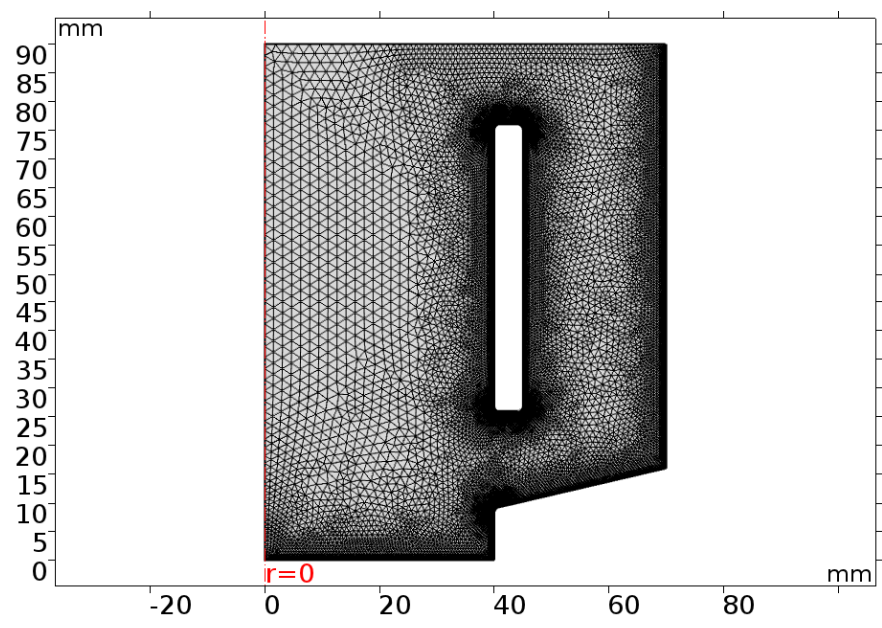

Figure 3: The geometry and mesh used for computations.

The above system of equations was solved using the Galerkin Finite Element Method in COMSOL Multiphysics 5.3a. A 2D asymmetric geometry was created using measurements from the actual reactor, and the computational domain was discretised using 24200 tetrahedral mesh elements as shown in Figure 3. The number of degrees of freedom solved was 576419, and the computational time was approximately 18 hours on a PC with an Intel core i5 64bit $2.7 \mathrm{GHz}$ processor. 


\subsection{Results and Discussion}

4.1 Effect of the membrane type on the plasma characteristics

As two different membranes were used to generate different bubble sizes, it is important to verify that this had no

effect on the plasma characteristics. The stainless steel and nickel membranes can in principle alter the electrical characteristics of the device and thus change the resonant frequency of the circuit as well as the characteristics of the plasma.

To study the effect of the membrane material on the plasma characteristics, each membrane was installed in the reactor and a plasma discharge was formed at the highest possible frequency of $36 \mathrm{kHz}$ followed by a gradual reduction to the lowest ignition frequency at $23 \mathrm{kHz}$ in steps of $2 \mathrm{kHz}$. Given the resonant nature of the power supply, sweeping the frequency range resulted in a variation of the applied voltage and thereby the power delivered to the plasma. To prevent thermal damage to the plasma module, the discharge was modulated using an on-time of $100 \mathrm{~ms}$ and an off-time of $233 \mathrm{~ms}$, i.e. a duty cycle of $30 \%$. Figure 4 shows the average power delivered to the discharge as a function of the applied frequency, and Figure 4(b) shows the relationship between the varying power and the applied voltage. These results indicate that both membranes behave similarly electrically and that the resonant frequency of the system is $28 \mathrm{kHz}$. When driven at this frequency, the applied voltage is $9.2 \mathrm{kV}$ and the power dissipated in the system at a $30 \%$ duty cycle is $25 \mathrm{~W}$. 

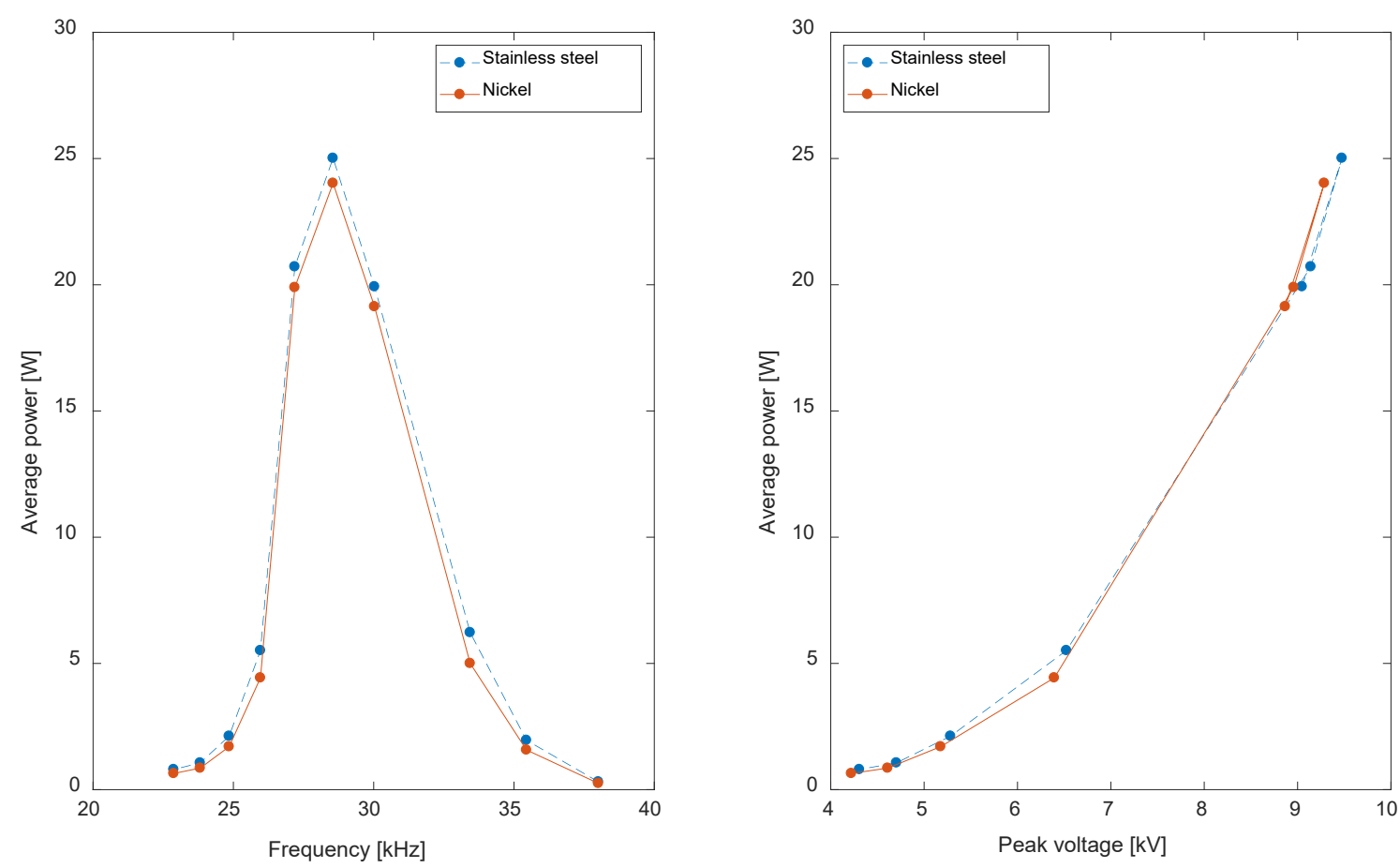

Figure 4: The effect of the membrane on the electrical characteristics of the system when this is driven with a duty cycle of $30 \%$. (a) Average power as a function of the driving frequency. (b) Relationship between the applied peak voltage and the average power.

Analysis of the OES provides details about the composition and temperature of the plasma. These depend on feed gas composition and applied power. Although it is possible to operate the plasma in pure oxygen and avoid production of RNS, high local temperatures in the plasma module $\left(\sim 150^{\circ} \mathrm{C}\right)$ and electronegative properties of oxygen could lead to unsafe operation. For this reason, pure oxygen plasmas were omitted from this study. Three feed gases were used in this study: synthetic air with no humidity $(\mathrm{RH} \%=0)$, synthetic humid air $(\mathrm{RH} \%=100)$ and pure nitrogen $(\mathrm{RH} \%=0)$. The relatively small discharge gap $(1 \mathrm{~mm})$ between the quartz crucibles and the metallic membrane makes it possible to strike the plasma with the three feed gases used. The frequency was fixed at 33 $\mathrm{kHz}$, slightly above the resonant frequency, to limit the amount of power delivered to the discharge and to minimize stress on the membranes and the power supply. At this frequency the applied peak voltage is $9 \mathrm{kV}$ and the average power dissipated in the system is $33 \mathrm{~W}$.

Humidity of the feed gas was introduced by bubbling the gas though water in a sintered dreschel bottle upstream of the reactor. High humidity in feed gas is well-known to increase hydrogen peroxide production at the expense of ozone (McKay et al., 2012). Pipa et al., 2007 observed a 50\% increase in the emission at $308 \mathrm{~nm}$, which corresponds to hydroxyl radicals, when humidity was introduced in the feed gas. In plasmas, $\cdot \mathrm{OH}$ is primarily 
produced by collisional dissociation of water molecules and these recombine readily to form hydrogen peroxide $\left(\cdot \mathrm{OH}+\cdot \mathrm{OH} \rightarrow \mathrm{H}_{2} \mathrm{O}_{2}\right)$. The presence of humidity in the gas increases the electronegativity of the plasma and for a given input power, the intensity of the discharge decreases. Nonetheless, it was possible to sustain a stable discharge at all the conditions considered in this study. 

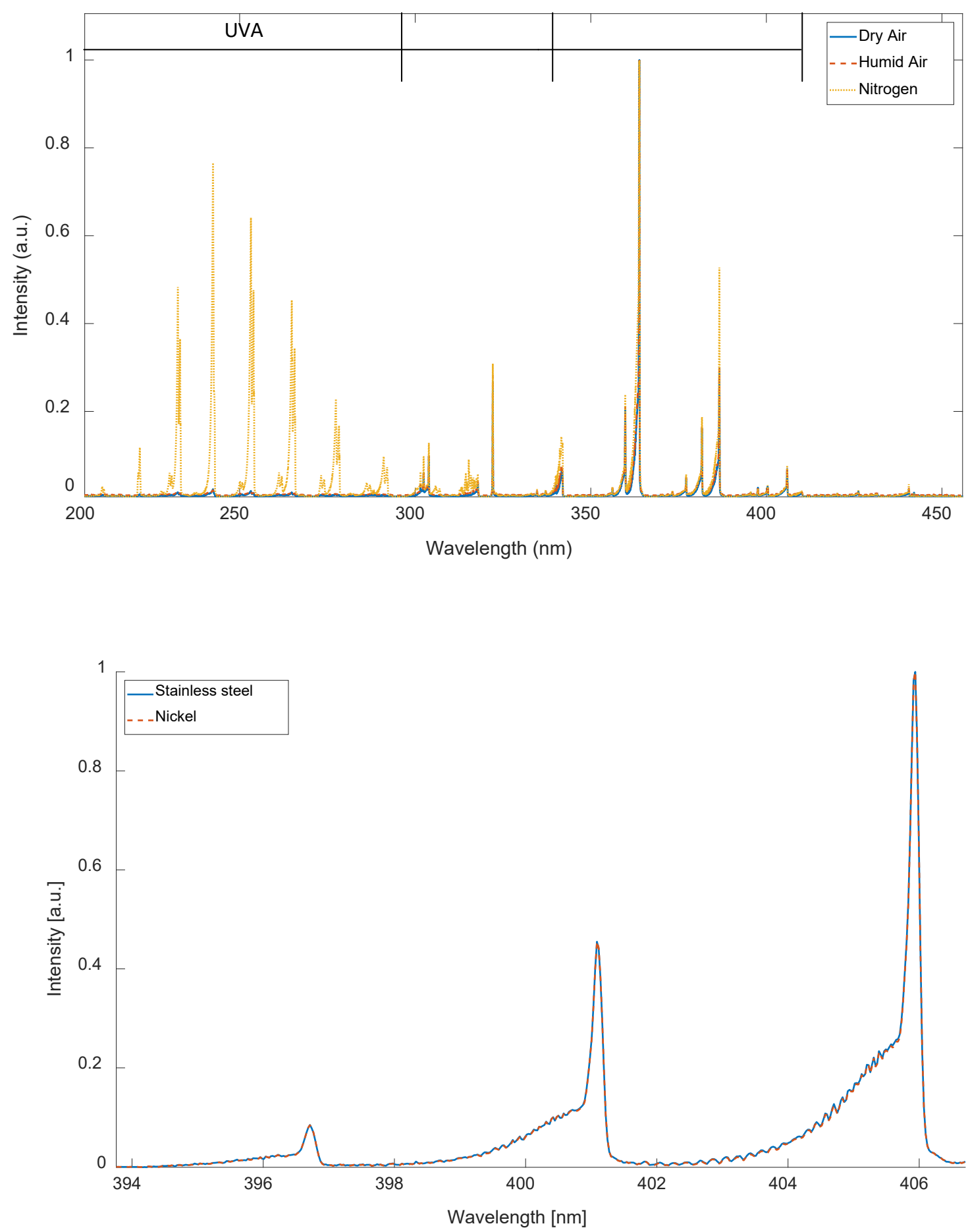

Figure 5: (a) OES for dry air $(\mathrm{RH}=0 \%)$, humid air $(\mathrm{RH}=100 \%)$ and nitrogen feed gas $(\mathrm{RH}=0 \%)$. (b) Comparison of the optical emission of dry air plasmas $(\mathrm{RH}=0 \%)$ sustained with the stainless steel and the nickel membranes.

Nitrogen is largely responsible for emission of UVA, UVB and UVC with excited NO radiating in the UVA region and $\mathrm{N}_{2}$ and $\mathrm{N}_{2}{ }^{+}$in the remainder (Schwartz et al., 2016). Figure 5 shows a significant increase in UVA emission 
from the plasma due to $\mathrm{NO}$ when pure nitrogen is used. In this case $\mathrm{O}$ is present due to impurities in the feed gas and minute amounts of oxygen are known to favour NO formation (Pipa et al., 2007). If substantial amount of oxygen is present in the feed gas and ozone is produced, ozone can absorb UVA (Grebenshchikov et al., 2007). OES was also used to compare the plasma discharge when different membranes were used. As shown in Figure 5(b) two spectra overlap confirming that the plasma characteristics are the same for each membrane and therefore the membrane has no noticeable effect on the plasma discharge. Further analysis of $(0-3)$ transition of the nitrogen second positive system indicates a rotational temperature of nitrogen molecules of $415 \pm 20 \mathrm{~K}$.

\subsection{Bubble Size Characterisation}

To determine the effect of membrane type on bubble generation, the bubble size distributions obtained with each membrane were recorded and analysed. Figure 6(a) and 6(b) show typical images of the bubbles generated with the stainless steel and the nickel membranes. The corresponding average bubble sizes are $2500 \mu \mathrm{m}$ and $550 \mu \mathrm{m}$, respectively. The reason for the larger bubbles produced by the stainless-steel membrane is twofold: firstly, the pore size for the stainless-steel membrane is 1.75 times larger than that for the nickel membrane. Whilst the pore size is not directly proportional to the bubble size, they are strongly linked, and the relationship between these two depends on the bubble generating regime (Bari and Robinson, 2013). Secondly, nickel membranes have a larger pitch of $180 \mu \mathrm{m}$ as opposed to $35 \mu \mathrm{m}$ for the stainless-steel membranes, and this reduces bubbles coalescence. The pore structure is also known to influence the bubble size distribution as seen in Figure 6(c) and 6(d). Interestingly, the bubble size distribution for the stainless-steel woven mesh is unimodal and positivelyskewed whilst the nickel membrane produces a bimodal distribution. Bubble overlap and coalescence is thought to be the main reason for larger bubbles being produced by the woven stainless-steel membrane. For the nickel membrane, the mean bubble size is slightly smaller than the most frequent bubble size due to very smaller bubbles generated at the edge of the membrane. 

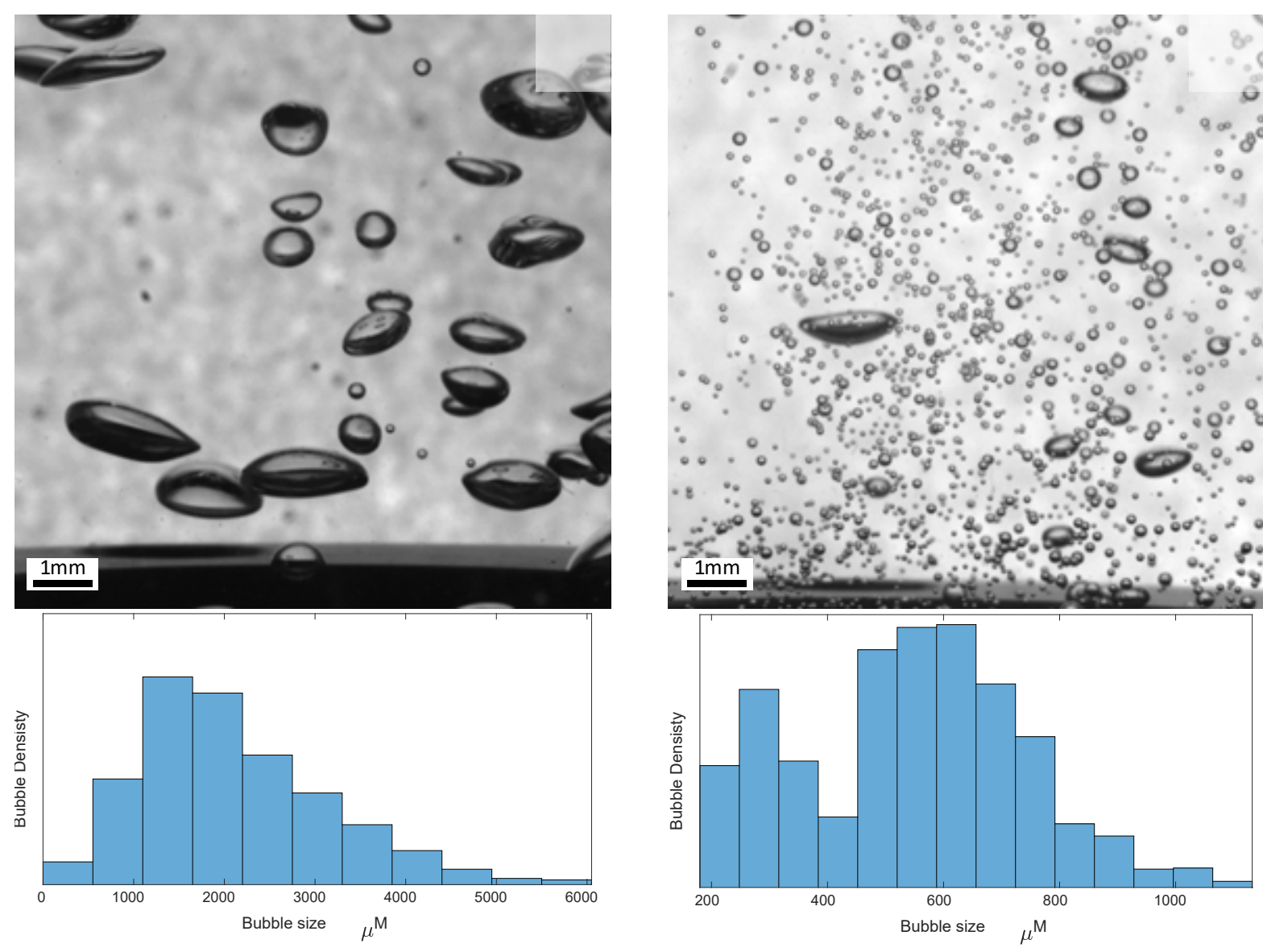

Figure 6: Bubble images and respective bubble size distributions (a and c) for a stainless-steel woven membrane with a wire diameter and a pitch of $30 \mu \mathrm{m}$ and $35 \mu \mathrm{m}$, respectively; (b and d) for a nickel membrane with a pore diameter and a pitch of $20 \mu \mathrm{m}$ and $180 \mu \mathrm{m}$, respectively.

The contact angle at the membrane surface is one of the key factors in bubble formation and detachment. It is known that smaller contact angles provide an early pinch-off during the bubble formation process, thus generating smaller bubbles (Kukizaki and Wada, 2008). Due to the high porosity of the woven stainless steel membrane, contact angle measurements were difficult, but the contact angle was estimated to be $\sim 85^{\circ}$ according to Prajitno et al., 2016. This value is smaller than the measured contact angle for nickel membranes, which is $120^{\circ}$. Therefore, further reduction of the bubble size could be made by surface modification of the nickel membrane. Despite the nickel membrane having the larger contact angle of the two membranes used, it still produced smaller bubbles mainly due to the membrane structure, specifically the pitch between the pores. Since the bubble size is much larger than the pitch for the stainless-steel membranes, bubbles coalesce immediately after formation generating larger bubbles. Energy efficient fluidic oscillator mediated microbubble generation technique can also be applied 
to achieve smaller bubbles $\sim 80-120 \mu \mathrm{m}$ (Rehman et al., 2015). Since the gas flow rate is fixed at 0.75 SLPM for both membranes, the smaller bubbles produced by the nickel membrane will have a higher surface area to volume ratio than those produced with the stainless-steel membrane; thereby improving the mass transfer rate from the gas to the liquid phase (Rehman et al., 2015).

\subsection{Species Concentrations in the Plasma Effluent}

As the numerical model requires the concentration of long-lived reactive species as an input, these were measured using FTIR and UV-absorption spectroscopy when the reactor was run without liquid. These concentrations were recorded as a function of time until a steady value was reached. It took approximately 15 minutes to reach steady values, which can be attributed to the time taken to completely flush the reactor and the FTIR gas column with plasma effluent replacing air. While a large number of RNS and ozone can be measured, some species such as $\mathrm{H}_{2} \mathrm{O}_{2}, \mathrm{HNO}_{2}$ and $\mathrm{NO}_{3}$ fell below the detection limit of FTIR or had overlapping peaks with other species; therefore the concentrations of those species were estimated from the computational results of Sakiyama et al., 2012. Concentrations of the reactive species achieved with a $30 \%$ duty cycle were then converted into partial pressures using the ideal gas law (see Table 2).

Table 2: The partial pressures of species in the gas phase measured from FTIR and UV-absorption spectroscopy. * calculated partial pressures from Sakiyama et al., 2012.

\begin{tabular}{|l|c|}
\hline Reactive Species & Partial pressure (Pa) \\
\hline $\mathrm{NO}_{2}$ & $1.8 \times 10^{-1}$ \\
\hline $\mathrm{NO}_{3} *$ & $1.8 \times 10^{-1}$ \\
\hline $\mathrm{N}_{2} \mathrm{O}_{5}$ & $5.1 \times 10^{1}$ \\
\hline $\mathrm{HNO}_{2} *$ & $5.7 \times 10^{-2}$ \\
\hline $\mathrm{HNO}_{3}$ & $5.7 \times 10^{1}$ \\
\hline $\mathbf{O}_{3}$ & $5.7 \times 10^{2}$ \\
\hline $\mathrm{H}_{2} \mathrm{O}_{2} *$ & $1.8 \times 10^{-1}$ \\
\hline $\mathrm{N}_{2} \mathrm{O}^{*}$ & $2.9 \times 10^{2}$ \\
\hline $\mathbf{O}_{2}$ & $1.7 \times 10^{4}$ \\
\hline $\mathbf{N}_{2}$ & $7.0 \times 10^{4}$ \\
\hline
\end{tabular}

Whilst a broad range of ROS and RNS species can be produced in atmospheric plasmas, the ratio between the two categories of species can be manipulated by changing the on-time and the duty cycle of the modulation (Ma et al., 2016; Seri et al., 2019). Lower duty cycles result in lower device temperatures, which is preferable for ozone production and minimisation of RNS production. Raising the duty cycle increases the average power delivered to 
the device and thereby its operating temperature. If sufficient cooling is provided, then the ozone density will increase. However, if the temperature increases, thermal decomposition of ozone will become significant and the plasma will predominantly produce RNS. The optimal duty cycle for ozone production therefore differs between reactors and systems. As the plasma module is cooled by both the gas flux that flows through the system and the water above which acts as a heat sink, high operating duty cycles of up to $60 \%$ can generate large ozone concentrations without the need for additional cooling mechanisms.

\subsection{Model Predictions}

Dissolved ozone concentration for each membrane was compared with that of the numerical simulations. Additionally, a smaller bubble size of $200 \mu \mathrm{m}$ was also investigated numerically as it could be possible to generate these bubbles using a microbubble generator based on fluidic oscillations (Zimmerman et al., 2011). The dissolved ozone concentration for both membranes were monitored for 15 minutes and compared with the numerical simulations (Figure 7).

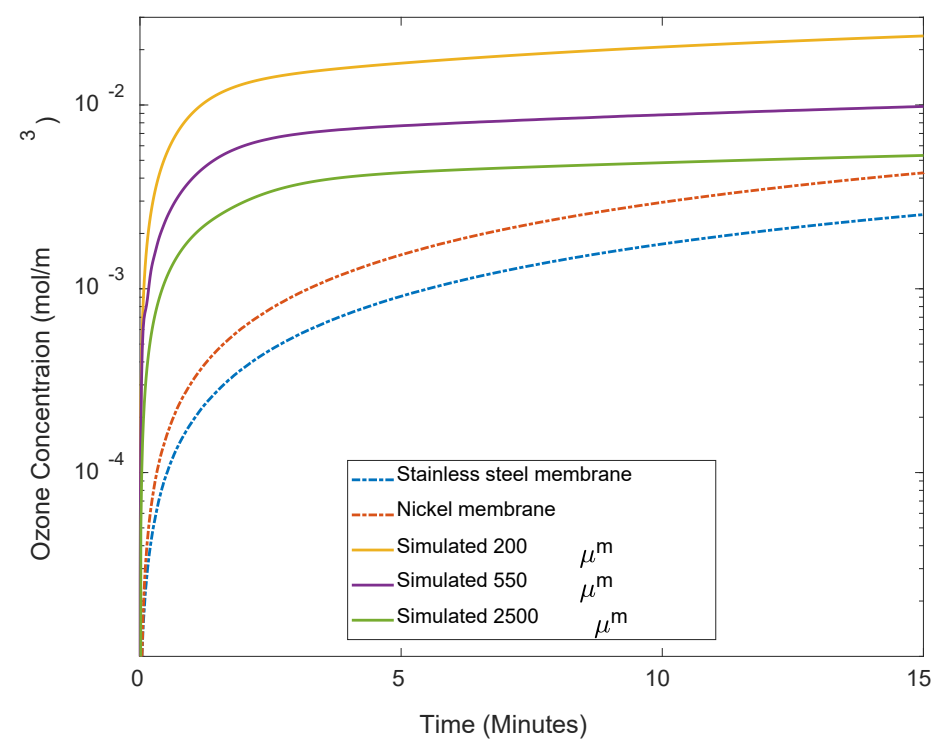

Figure 6: Comparison between experimental measurements and computational results of the time evolution of the dissolved ozone concentration.

Both the computed and the measured ozone concentration evolutions show a similar trend: a rapid rise for the first few minutes followed by a plateauing behaviour. This is expected as the driving force for mass transfer is high at the beginning but reduces with time as more ozone is dissolved in the liquid. Furthermore, chemical reactions will 
intensify as the reactive species concentration rises. For both simulated and experimental profiles, higher concentrations are achieved for the smaller bubbles. After 15 minutes of bubbling, the nickel membrane achieved $\sim 60 \%$ higher ozone concentration than the stainless-steel membrane while simulation results show an increase of $\sim 54 \%$ for $550 \mu \mathrm{m}$ bubbles as compared to $2500 \mu \mathrm{m}$ bubbles. However, there is some discrepancy between the simulated and the experimental values. Simulation results predict a faster initial increase and higher final value than those observed in the experiments. These quantitative differences are attributed to the uncertainties in the mass transfer rate and chemical kinetics used in the simulation. The correlation constants used in equation (5), X and $\mathrm{Y}$, are guidelines for a broad bubble range rather than a specific bubble size and do not account for the influence of different gas composition. However, gas molecules could alter the properties of the gas-liquid interface (Zheng et al., 2015) and thus, change the mass transfer rate. In addition, the model does not take into consideration the bubble size distribution observed in the experiments and ozone leaving the liquid at the top boundary. Surface reactions on the inner walls of the acrylic tank, the internal draft tube and the membrane were not accounted for in the model. Although it is well known that reactive species react with polymers and metals, these reactions and their rates are not well-defined.

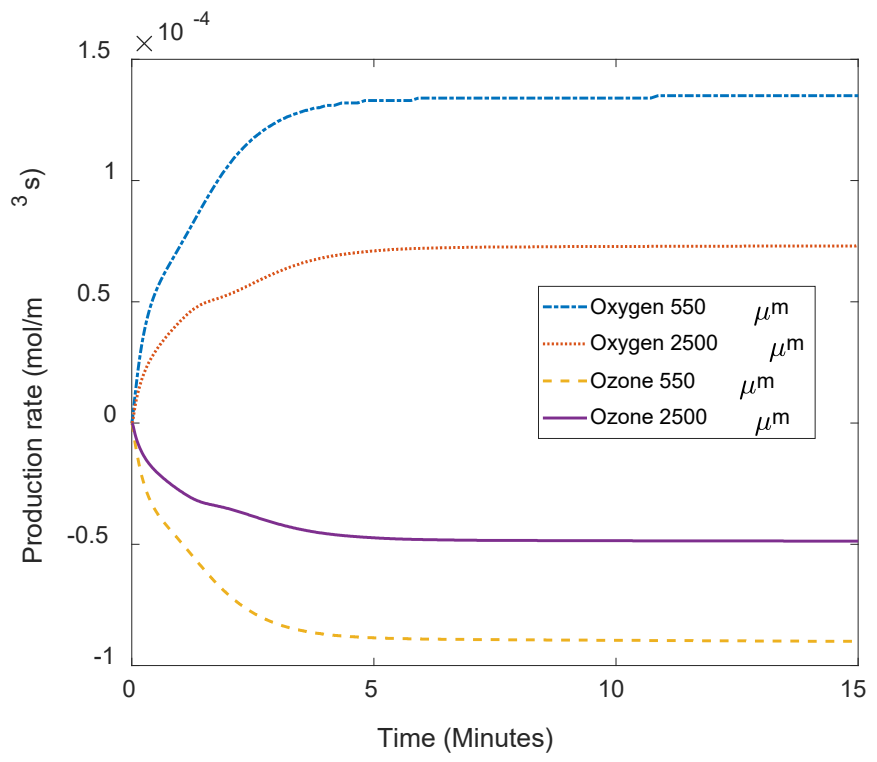

Figure 7: Production rates of species (ozone and oxygen) from the numerical simulations.

Figure 8 shows the average production/loss rate of oxygen and ozone in the liquid due to chemical reactions in the liquid phase. As oxygen is more stable than ozone, oxygen is largely produced, and ozone consumed through numerous chemical pathways largely involving reaction with $\mathrm{H}_{2} \mathrm{O}_{2}, \cdot \mathrm{OH}$ and $\mathrm{HO}_{2}$. A positive rate indicates 
creation of that species while a negative rate indicates consumption of that species. For both species, the first three minutes show a rapid change in the production/consumption rate before reaching a steady state. According to Figure 8, ozone is consumed by chemical reactions with other reactive species while oxygen is being produced.

It is interesting to evaluate various approaches for increasing dissolved ozone concentration in the liquid phase for applications that require substantial oxidation or disinfection capability. This can be achieved either by decreasing the bubble size leading to higher mass transfer rates or increasing the ozone concentration in the plasma effluent at the expense of higher input energy. These options were investigated by computing the average dissolved ozone concentration for bubbles 2.75 times smaller than $550 \mu \mathrm{m}$ (i.e. $200 \mu \mathrm{m}$ bubbles) and for partial pressure of ozone 2.75 higher than the measurements used in actual experiments (1570 Pa) with $550 \mu \mathrm{m}$ bubbles. The results are summarised in Table 3. By reducing the bubble size from $550 \mu \mathrm{m}$ to $200 \mu \mathrm{m}$, the dissolved ozone concentration can be increased by a factor of 2.4 while increasing the partial pressure only doubles the dissolved ozone concentration. This result is not surprising as increasing the partial pressure increases the mass transfer linearly while reducing the bubble diameter affects mass transfer non-linearly according to equation (5). This significant increase in mass transfer due to smaller bubbles was also observed in Figure 7. Decreasing the bubble size is therefore a more effective approach to increase the concentration of dissolved reactive species than increasing the partial pressure. Partial pressure of ozone in the plasma effluent can be increased by operating the reactor at higher duty cycles with additional cooling, but this is likely to increase power consumption and design complexity. This result highlights the importance of utilising small bubbles to enhance the mass transfer as opposed to increase production rates at a higher energy cost.

Table 3: The effect of bubble size and partial pressure on the dissolved ozone concentration after 15 minutes.

\begin{tabular}{|c|c|c|c|}
\hline Bubble size $(\boldsymbol{\mu m})$ & $\begin{array}{c}\text { Ozone partial } \\
\text { pressure }(\mathbf{p a})\end{array}$ & $\begin{array}{c}\text { dissolved ozone } \\
\text { concentration }\left(\mathbf{m o l} / \mathbf{m}^{\mathbf{3}}\right)\end{array}$ & $\begin{array}{c}\text { Concentration } \\
\text { increase factor }\end{array}$ \\
\hline $\mathbf{5 5 0}$ & 571 & $9.8 \times 10^{-3}$ & 1 \\
\hline $\mathbf{5 5 0}$ & 1570 & $1.9 \times 10^{-2}$ & 2 \\
\hline $\mathbf{2 0 0}$ & 571 & $2.3 \times 10^{-2}$ & 2.4 \\
\hline
\end{tabular}

\subsection{Effect of the Bubble Size on Fluid Flow}

Average bubble sizes measured for each membrane were used as model inputs to determine the effect of bubble size on fluid velocity due to buoyant convection. Due to limitations in the model, a single average bubble size instead of a distribution was used in the simulations. Resultant velocity fields at different times are shown in 
Figure 9. Both bubble sizes induced similar flow features. As bubbles are released from the porous membrane at the bottom of the reactor, they rise within the draft tube imparting a drag force on the liquid that depends on the rise velocity and the surface area of the bubbles. Most bubbles will leave at the top liquid surface and the liquid will be driven downward in the outer downcomer region, thereby inducing a circulatory flow pattern. Several stagnant points are developed at the corners of the reactor, but these regions are limited to a very small volume by design and represent areas for further future improvement. The model shows that the flow field takes approximately 10 seconds to reach a steady state once bubbling starts. As shown in Figure 9, the velocity magnitude induced by the smaller bubbles is one order of magnitude larger than that induced by the larger bubbles. Since the net volume of gas is fixed for both cases, the difference in velocity magnitude is mainly due to the difference in interfacial area, which is $2.13 \times 10^{-7} \mathrm{~m}^{-1}$ and $3.06 \times 10^{-8} \mathrm{~m}^{-1}$ for $550 \mu \mathrm{m}$ and $2500 \mu \mathrm{m}$ bubbles respectively. Although high radial velocity under the draft tube could push bubbles towards the centre of the tank, leading to bubble coalescence, this effect is negligible for cases studied.
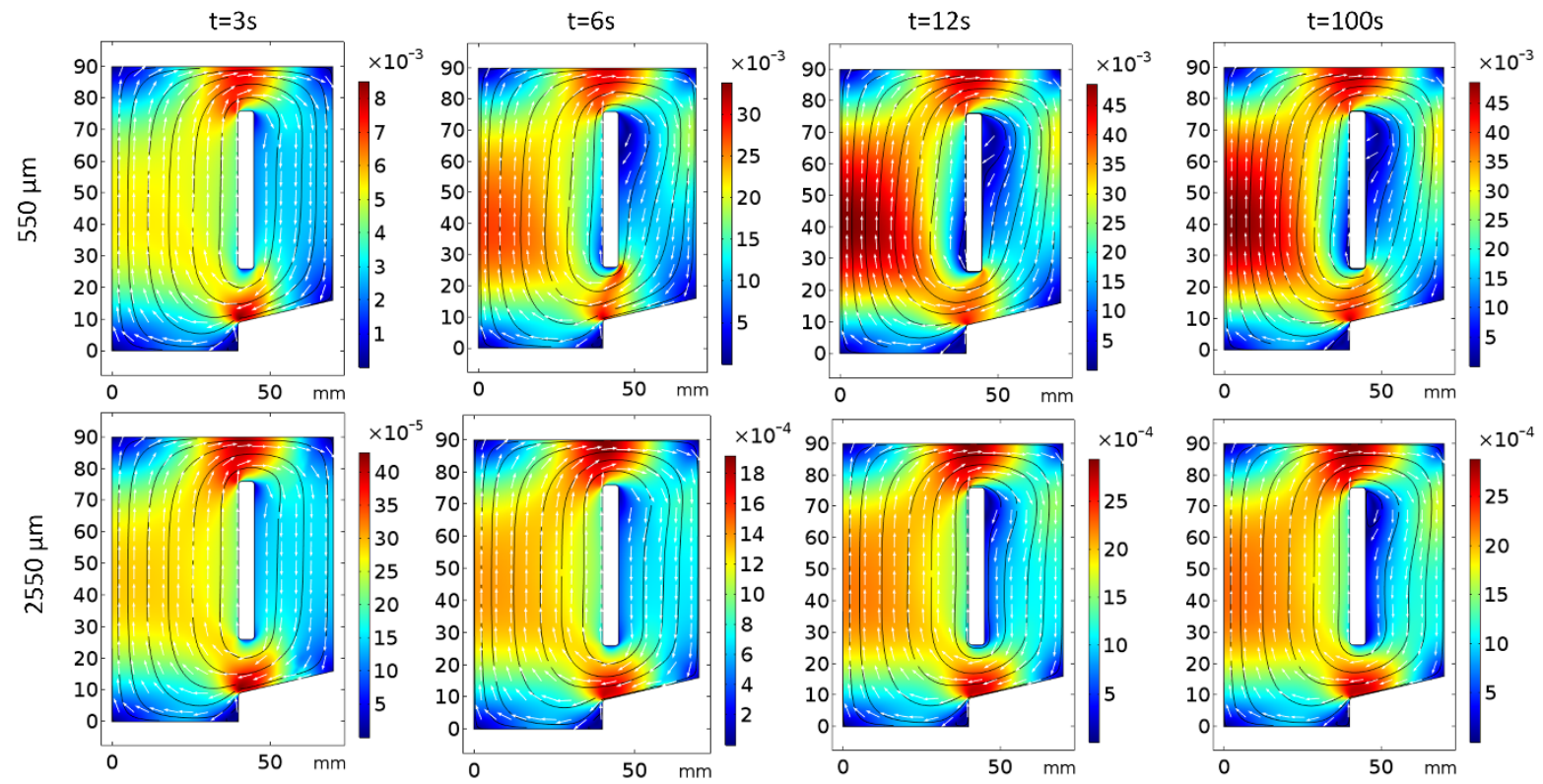

Figure 8: Simulated fluid flow profiles $\left(\mathrm{m} \mathrm{s}^{-1}\right)$ for average bubble sizes produced by the nickel $(550 \mu \mathrm{m})$ and the stainless-steel $(2550 \mu \mathrm{m})$ membranes.

\subsection{Time Evolution of Species}

The numerical model can be used to study the time evolution of various ROS and RNS produced within the liquid phase to determine the suitability of the reactor for different applications. Figure 10 shows the time evolution of the concentrations of various species in the liquid phase for the first 15 minutes of operation. Computational 
results for the case with $550 \mu \mathrm{m}$ bubbles (nickel membrane) are presented here as $550 \mu \mathrm{m}$ bubbles result in higher mass transfer rates and higher final concentrations than larger bubbles studied here (Figure 7).

Figure 10(a) shows concentrations of ROS in the liquid phase. Ozone and hydrogen peroxide are transferred from bubbles to the liquid and undergo further reactions within the liquid. Their concentration increases gradually over time. As their concentration rises within the liquid, $\mathrm{O}_{3}$ and $\mathrm{H}_{2} \mathrm{O}_{2}$ participate in reactions with other ROS and RNS species. Formation of $\cdot \mathrm{OH}$ by direct interaction between $\mathrm{O}_{3}$ and $\mathrm{H}_{2} \mathrm{O}_{2}$ is an important reaction (equation 9).

$$
\mathrm{O}_{3}+\mathrm{H}_{2} \mathrm{O}_{2} \rightarrow \cdot \mathrm{OH}+\mathrm{HO}_{2}+\mathrm{O}_{2}
$$

AOP systems based on pure ozone generation systems require addition of peroxide to form $\cdot \mathrm{OH}$, but since APPs generates both ozone and hydrogen peroxide, addition of peroxide is not required. According to Figure $10(\mathrm{a}), \cdot \mathrm{OH}$ reach a steady state concentration of $3 \times 10^{-9} \mathrm{~mol} / \mathrm{m}^{-3}$ after 2 minutes. $\cdot$ OH have a half-life of $\sim 1 \mathrm{~ns}$, therefore constant generation of $\cdot \mathrm{OH}$ within the liquid by chemical reactions is important.

According to the computational study, the $\mathrm{pH}$ drops from 7 to 5.9 after 15 minutes of bubbling. For the experiments, $\mathrm{pH}$ reduced to $\sim 3.5$ after $1 \mathrm{hr}$ of operation. Acidification of the liquid is mainly due to RNS such as $\mathrm{HNO}_{2}, \mathrm{HNO}_{3}, \mathrm{ONOOH}$ and $\mathrm{O}_{2} \mathrm{NOOH}$ (Figure $10(\mathrm{c})$ ) and $\mathrm{H}_{2} \mathrm{O}_{2}$. All these species accumulate in the liquid and dissociate into their ionic states, releasing $\mathrm{H}^{+}$as shown in Figure 10(b) and (d). The $\mathrm{pH}$ of the solution may influence reactions that occur in the liquid phase in which $\mathrm{H}^{+}$and $\mathrm{OH}^{-}$participate as reactants. Also, mass transfer rates are affected by $\mathrm{pH}$ as this affects the solubility of gases. For instance, acidic conditions increase the Henry's constant for ozone by $70 \%$ when the pH decreases from 7 to 2 (Biń, 2006; Kuosa et al., 2004). The dependency of Henry's constant on $\mathrm{pH}$ is not accounted for in the model as data is not available for all species considered. 

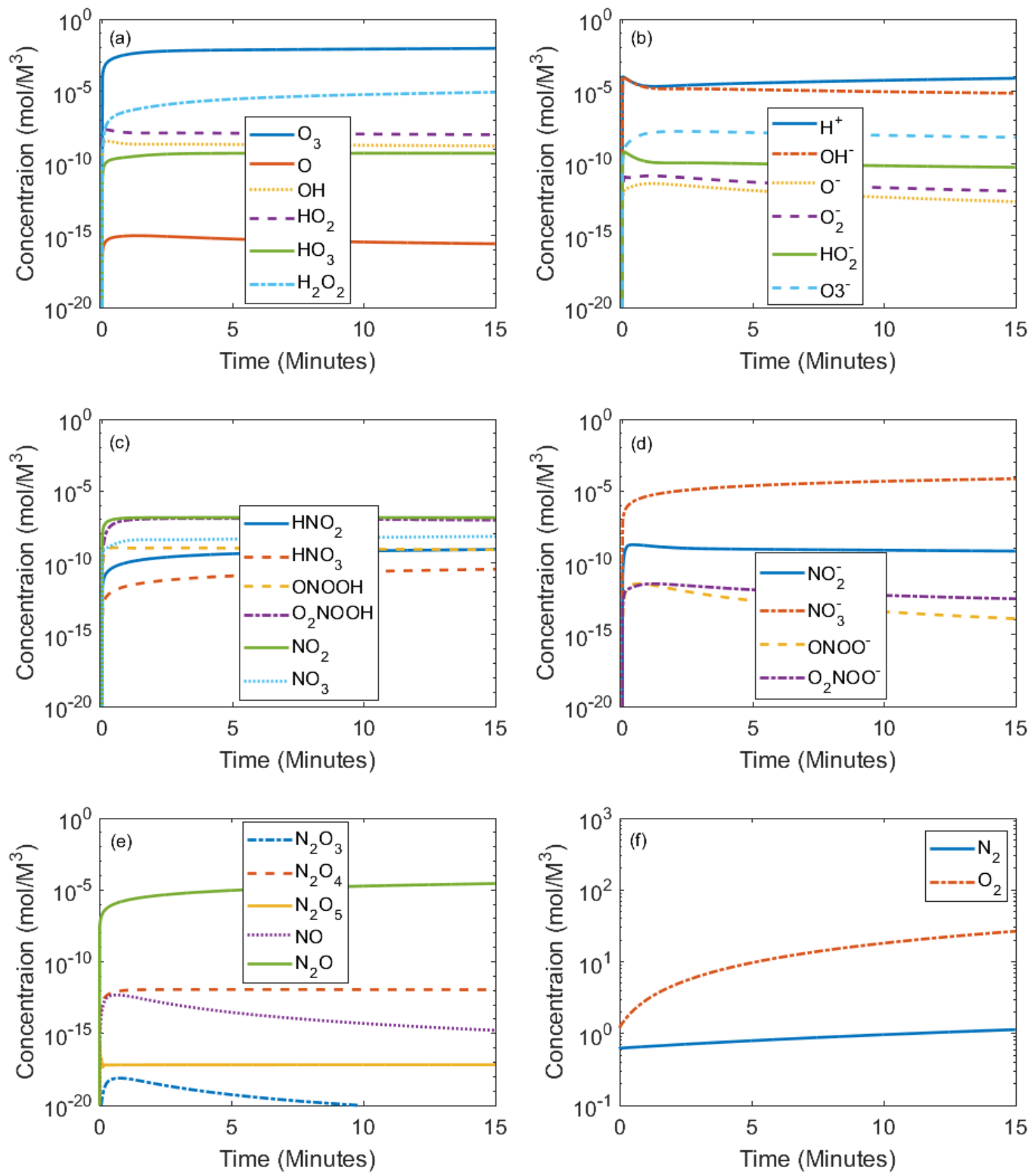

Figure 9: Concentration of species in the liquid phase for $550 \mu \mathrm{m}$ bubbles (a) neutral ROS, (b) ionic ROS, (c) neutral RNS containing $\mathrm{H}$, (d) ionic RNS (e) neutral RNS without $\mathrm{H}$ and (f) $\mathrm{N}_{2}$ and $\mathrm{O}_{2}$.

Figure 10(b) and 10(d) show the main ionic species present in the liquid phase. Ionic RNS are typically formed by reaction of neutral RNS, such as $\mathrm{N}_{2} \mathrm{O}_{4}$ and $\mathrm{N}_{2} \mathrm{O}_{5}$ (Figure $10(\mathrm{e})$ ) with water to form $\mathrm{NO}_{2}{ }^{-}$and $\mathrm{NO}_{3}{ }^{-}$, respectively (equation 9 and 10). 


$$
\begin{array}{cc}
\mathrm{N}_{2} \mathrm{O}_{4}+\mathrm{H}_{2} \mathrm{O} \rightarrow \mathrm{NO}_{2}^{-}+\mathrm{NO}_{3}^{-}+2 \mathrm{H}^{+} & \text {(9)(Coddington et al., 1999) } \\
\mathrm{N}_{2} \mathrm{O}_{5}+\mathrm{H}_{2} \mathrm{O} \rightarrow 2 \mathrm{NO}_{3}^{-}+2 \mathrm{H}^{+} & (10)(\text { Herrmann et al., 2000) }
\end{array}
$$

Ionic ROS are typically formed from species such as hydrogen peroxide that react with water to form $\mathrm{H}^{+}$and $\mathrm{HO}_{2}{ }^{-}$ (equation 10) with the latter then forming other ions such as $\mathrm{O}_{2}^{-}$(equation 12 and 13).

$$
\begin{array}{cl}
\mathrm{H}_{2} \mathrm{O}_{2} \leftrightarrow \mathrm{H}^{+}+\mathrm{HO}_{2}^{-} & \text {(11)(Pastina and LaVerne, 2001) } \\
\cdot \mathrm{OH}+\mathrm{HO}_{2}^{-} \rightarrow \mathrm{HO}_{2}+\mathrm{OH}^{-} & \text {(12)(Pastina and LaVerne, 2001) } \\
\mathrm{HO}_{2} \leftrightarrow \mathrm{H}^{+}+\mathrm{O}_{2}^{-} & \text {(13)(Coddington et al., 1999) }
\end{array}
$$

The increase in ionic concentration in the liquid suggests an increase in the electrical conductivity of the liquid, as it has been observed experimentally (Wright et al., 2018a). The combined effect of decreasing $\mathrm{pH}$ and increasing conductivity of the solution is advantageous in achieving high level of ozone in the tank as acidic conditions are known to slow down decomposition of ozone and increase the Henry's constant (Dehouli et al., 2010; Park et al., 2005). $\mathrm{N}_{2} \mathrm{O}$, a stable species generated in the plasma effluent, only reacts with $\mathrm{H}$ to form $\mathrm{OH}$ and $\mathrm{N}_{2}$; therefore, accumulates readily in the tank as shown in Figure 10 (e). Nitrogen concentration in the liquid increases only slightly as its solubility is low and nitrogen forming reactions are limited (Figure 10 (f)). However, $\mathrm{O}_{2}$ concentration increases 2 orders of magnitude as it is a common by-product of reactions involving ROS and RNS and it has a relatively high solubility.

\subsection{Application Development and Limitations}

Based on the characterisation of the reactor and the simulation results discussed above, it is possible to provide some generic guidance for the operation of the reactor for different applications. For the treatment of organic liquid suspensions, such as wastewater sludge or biomass pre-treatment, high concentrations of ROS are desirable; therefore, maximising power to the plasma module whilst avoiding increases in temperature is important. The input power to a plasma can be adjusted by either varying the amplitude of the applied voltage or its duty cycle. A duty cycle of $30 \%$ was used in this study, but duty cycles of up to $60 \%$ have been tested with this rig demonstrating the potential to further increase the ozone production. The reactor is designed to provide natural cooling to the plasma module by means of the incoming gas flow and liquid convection, but it may also be possible to operate the plasma continuously (without modulation) if additional cooling is provided (e.g. forced convection, water cooling of electrodes, etc). Whilst the focus on this study was to maximise dissolved ozone concentration 
in the liquid phase, hydrogen peroxide was also formed in the plasma and transferred to the liquid. The ratio between these two species can be controlled by changing the humidity level in the feed gas to the plasma. i.e. an increase in humidity favours hydrogen peroxide over ozone (Vasko et al., 2014). $\mathrm{H}_{2} \mathrm{O}_{2}$ and superoxide are known to produce $\mathrm{OH}$ in the presence of transition metals through the Fenton and Haber-Weiss reactions; hence it could provide excellent antimicrobial properties (Foster et al., 2012).

These experiments were performed in distilled water with the view of understanding the fluid dynamics, mass transfer and chemistry for dilute solutions and suspensions. However, some applications may require processing liquids with high amount of suspended matter or highly viscous solutions. Even though smaller bubbles in the order of $\sim 200 \mu \mathrm{m}$ were shown to perform better in terms of mass transfer and mixing, changing the fluid properties will affect this result. As the bubble size reduces, the terminal rise velocity of bubbles will decrease reducing the drag force on the fluid. As a consequence, viscous liquids will have low velocities and air-lift driven mixing will be weak. If large amount of suspended matter is present in the process fluid such as wastewater sludge or concentrated biomass suspensions, then additional mixing may be required to complement the effect of the small bubbles. Alternatively, a broad size distribution or bimodal bubble size distribution can be used to achieve both: i.e. large bubbles for mixing and microbubbles for improved mass transfer. While the bubble size range used in this study is more appropriate for dilute solutions and suspensions with fluid properties similar to that of water, bubble size selection for viscous liquids with high concentrations of suspended matter require further investigation.

\subsection{Conclusions}

This manuscript reports on the design, characterisation and modelling of a novel plasma-microbubble reactor for the treatment of dilute solutions and suspensions. In this reactor, plasma is formed in the immediate vicinity of the gas-liquid interface to favour effective delivery of short-lived reactive species from the gas plasma to the liquid. Mass transfer of long-lived reactive species is enhanced using microbubbles. Perforated nickel and woven stainless-steel membranes were used to generate $\sim 550 \mu \mathrm{m}$ and $\sim 2500 \mu \mathrm{m}$ bubbles, respectively. A numerical model of the reactor was developed to study the time evolution of various reactive species and the effect of bubble size on the overall performance of the reactor. The model accounts for bubbly flow, interfacial mass transfer, transport of species and chemical reactions.

The reactor was found to be effective in delivering ROS and RNS to a liquid phase and generated plasma with the same composition and temperature with both membranes. The use of the nickel membrane created smaller bubbles $(\sim 550 \mu \mathrm{m})$, which resulted in efficient mass transfer of reactive species into the liquid phase. This enhanced mass 
transfer caused a rapid increase and higher final concentrations of reactive species in the liquid phase for the same input conditions to the reactor. The smaller bubble size also influenced the mixing of the liquid, and the fluid velocities induced by the airlift-loop configuration were found to be one order of magnitude larger for smaller bubbles than for larger bubbles. Analysis of the chemistry of the model showed that hydrogen peroxide and ozone are the most abundant species accumulating in the liquid and that these react in the liquid phase to produce shorterlived species such as hydroxy radicals, which are desirable in many applications. This study also demonstrates the ability to alter plasma chemistry to suit an application by regulating the feed gas and the power source delivery.

\section{Acknowledgements}

The authors would like to acknowledge grants POC-HD_RD0300 C from Plants to Products network of BBSRC NIBB and BB/L013819/1. Also, they would also like to acknowledge the use of the facilities and the technical assistance of Keith Yendall from the Loughborough Materials and Characterisation Centre (LMCC) of Loughborough University for the SEM analyses. The authors are grateful to Anthony Eyre, Mark Barron and Steve Bowler for the fabrication of the reactor as well as Graham Moody and Tim Coles for technical assistance. AW would like to acknowledge the school of ACCME, Loughborough University and EPSRC (EP/M507908/1) for the PhD studentship.

\section{References}

Al-mashhadani, M.K.H., Bandulasena, H.C.H., Zimmerman, W.B., 2012. CO 2 Mass Transfer Induced through an Airlift Loop by a Microbubble Cloud Generated by Fluidic Oscillation 1864-1877.

AL-Mashhadani, M.K.H., Wilkinson, S.J., Zimmerman, W.B., 2015. Airlift bioreactor for biological applications with microbubble mediated transport processes. Chem. Eng. Sci. 137, 243-253. https://doi.org/10.1016/j.ces.2015.06.032

Bari, S. di, Robinson, A.J., 2013. Experimental study of gas injected bubble growth from submerged orifices. Exp. Therm. Fluid Sci. 44, 124-137. https://doi.org/10.1016/j.expthermflusci.2012.06.005

Biń, A.K., 2006. Ozone Solubility in Liquids. Ozone Sci. Eng. 28, 67-75. https://doi.org/10.1080/01919510600558635 
Bruggeman, P.J., Kushner, M.J., Locke, B.R., Gardeniers, J.G.E., Graham, W.G., Graves, D.B., Hofman-Caris, R.C.H.M., Maric, D., Reid, J.P., Ceriani, E., Fernandez Rivas, D., Foster, J.E., Garrick, S.C., Gorbanev, Y., Hamaguchi, S., Iza, F., Jablonowski, H., Klimova, E., Kolb, J., Krcma, F., Lukes, P., Machala, Z., Marinov, I., Mariotti, D., Mededovic Thagard, S., Minakata, D., Neyts, E.C., Pawlat, J., Petrovic, Z.L., Pflieger, R., Reuter, S., Schram, D.C., Schröter, S., Shiraiwa, M., Tarabová, B., Tsai, P.A., Verlet, J.R.R., von Woedtke, T., Wilson, K.R., Yasui, K., Zvereva, G., 2016. Plasma-liquid interactions: a review and roadmap. Plasma Sources Sci. Technol. 25, 053002. https://doi.org/10.1088/0963-0252/25/5/053002

Bruggeman, P.J., Sadeghi, N., Schram, D.C., Linss, V., 2014. Gas temperature determination from rotational lines in non-equilibrium plasmas: a review. Plasma Sources Sci. Technol. 23, 023001. https://doi.org/10.1088/0963$0252 / 23 / 2 / 023001$

Calderbank, P.H., Moo-Young, M.B., 1995. The continuous phase heat and mass transfer properties of dispersions. Chem. Eng. Sci. 50, 3921-3934. https://doi.org/10.1016/0009-2509(96)81823-9

Coddington, J.W., Hurst, J.K., Lymar, S. V., 1999. Hydroxyl radical formation during peroxynitrous acid decomposition. J. Am. Chem. Soc. 121, 2438-2443. https://doi.org/10.1021/ja982887t

Dalvi, S. V., Joshi, J.R., 2015. Modeling of microbubble dissolution in aqueous medium. J. Colloid Interface Sci. 437, 259-269. https://doi.org/10.1016/j.jcis.2014.09.044

Dehouli, H., Chedeville, O., Cagnon, B., Caqueret, V., Porte, C., 2010. Influences of pH, temperature and activated carbon properties on the interaction ozone/activated carbon for a wastewater treatment process. Desalination 254, 12-16. https://doi.org/10.1016/j.desal.2009.12.021

Fitzsimmons, C., Shawcross, J.T., Whitehead, J.C., 1999. Plasma-assisted synthesis of N 2 O 5 from NO 2 in air at atmospheric pressure using a dielectric pellet bed reactor. J. Phys. D. Appl. Phys. 32, 1136-1141. https://doi.org/10.1088/0022-3727/32/10/310

Foster, J., Sommers, B.S., Gucker, S.N., Blankson, I.M., Adamovsky, G., 2012. Prespectives on the Interaction of Plasmas With Liquid Water for Water Purification 40, 1311-1323.

Grebenshchikov, S.Y., Qu, Z.-W., Zhu, H., Schinke, R., 2007. New theoretical investigations of the photodissociation of ozone in the Hartley, Huggins, Chappuis, and Wulf bands. Phys. Chem. Chem. Phys. 9, 2044-2064. https://doi.org/10.1039/b701020f 
Hanotu, J.O., Bandulasena, H., Zimmerman, W.B., 2017. Aerator design for microbubble generation. Chem. Eng. Res. Des. 123, 367-376. https://doi.org/10.1016/j.cherd.2017.01.034

Hayes, J., Kirf, D., Garvey, M., Rowan, N., 2013. Disinfection and toxicological assessments of pulsed UV and pulsed-plasma gas-discharge treated-water containing the waterborne protozoan enteroparasite Cryptosporidium parvum. J. Microbiol. Methods 94, 325-337. https://doi.org/10.1016/j.mimet.2013.07.012

Herrmann, H., Ervens, B., Jacobi, H.W., Wolke, R., Nowacki, P., Zellner, R., 2000. CAPRAM2.3: A chemical aqueous phase radical mechanism for tropospheric chemistry. J. Atmos. Chem. 36, 231-284. https://doi.org/10.1023/A:1006318622743

Iza, F., Hopwood, J.A., 2004. Rotational, Vibrational, and Excitation Temperatures of a Microwave-Frequency Microplasma. IEEE Trans. Plasma Sci. 32, 498-504. https://doi.org/10.1109/TPS.2004.826145

Josh Smith, U.K.E., 2014. Chemistry for Antimicrobial Properties of Water Treated With Non-Equilibrium Plasma. J. Nanomedine. Biotherapeutic Discov. 04, 1-5. https://doi.org/10.4172/2155-983X.1000120

Kim, H.S., Cho, Y.I., Hwang, I.H., Lee, D.H., Cho, D.J., Rabinovich, A., Fridman, A., 2013. Use of plasma gliding arc discharges on the inactivation of E. Coli in water. Sep. Purif. Technol. 120, 423-428. https://doi.org/10.1016/j.seppur.2013.09.041

Koh, C.I., Lee, S.J., Kang, J.W., 2001. New UV-flux measurement method using ozone photolysis rate. OzoneScience Eng. 23, 245-253. https://doi.org/10.1080/01919510108962008

Kukizaki, M., Wada, T., 2008. Effect of the membrane wettability on the size and size distribution of microbubbles formed from Shirasu-porous-glass (SPG) membranes. Colloids Surfaces A Physicochem. Eng. Asp. 317, 146154. https://doi.org/10.1016/j.colsurfa.2007.10.005

Kuosa, M., Laari, A., Kallas, J., 2004. Determination of the Henry’s Coefficient and Mass Transfer for Ozone in a Bubble Column at Different $\mathrm{pH}$ Values of Water. Ozone Sci. Eng. 26, 277-286. https://doi.org/10.1080/01919510490455746

Laux, C.O., 2002. Physico-Chemical Modeling of High Enthalpy and Plasma Flows. Rhode-Saint-Genese, Belgium.

Liu, Z.C., Liu, D.X., Chen, C., Li, D., Yang, A.J., Rong, M.Z., Chen, H.L., Kong, M.G., 2015. Physicochemical 
processes in the indirect interaction between surface air plasma and deionized water. J. Phys. D. Appl. Phys. 48, 495201. https://doi.org/10.1088/0022-3727/48/49/495201

Loeb, B.L., Thompson, C.M., Drago, J., Takahara, H., Baig, S., 2012. Worldwide Ozone Capacity for Treatment of Drinking Water and Wastewater: A Review. Ozone Sci. Eng. 34, 64-77. https://doi.org/10.1080/01919512.2012.640251

Lucas, M.S., Peres, J.A., Lan, B.Y., Li Puma, G., 2009. Ozonation kinetics of winery wastewater in a pilot-scale bubble column reactor. Water Res. 43, 1523-1532. https://doi.org/10.1016/j.watres.2008.12.036

Ma, T., Jiang, H., Liu, J., Zhong, F., 2016. Decomposition of Benzene Using a Pulse-Modulated DBD Plasma. Plasma Chem. Plasma Process. 36, 1533-1543. https://doi.org/10.1007/s11090-016-9736-z

Manley, T.C., 1943. The Electric Characteristics of the Ozonator Discharge. Trans. Electrochem. Soc. 84, 83. https://doi.org/10.1149/1.3071556

McKay, K., Liu, D.X., Rong, M.Z., Iza, F., Kong, M.G., 2012. Generation and loss of reactive oxygen species in low-temperature atmospheric-pressure RF He $+\mathrm{O} 2+\mathrm{H} 2 \mathrm{O}$ plasmas. J. Phys. D. Appl. Phys. 45, 172001. https://doi.org/10.1088/0022-3727/45/17/172001

Multanen, V., Shulzinger, E., Whyman, G., Bormashenko, Y., Bormashenko, E., 2016. Electrostatic interaction between water droplets coated by cold plasma treated silicone oil. Quantification of cold plasmas charging of liquids. Colloids Surfaces A Physicochem. Eng. Asp. 509, 224-228. https://doi.org/10.1016/j.colsurfa.2016.09.014

Park, J.Y., Lee, J.D., Han, S.B., 2005. The effect of conductivity on active species products by electrical discharge with air bubbles in water. J. Adv. Oxid. Technol. 8, 205-211.

Pastina, B., LaVerne, J.A., 2001. Effect of molecular hydrogen on hydrogen peroxide in water radiolysis. J. Phys. Chem. A 105, 9316-9322. https://doi.org/10.1021/jp012245j

Pipa, A. V, Schmidt, M., Becker, K., 2007. Ultraviolet (UV) emissions from a unipolar submicrosecond pulsed dielectric barrier discharge (DBD) in He-Air mixtures. J. Phys. Conf. Ser. 86, 1-14. https://doi.org/10.1088/1742$6596 / 86 / 1 / 012014$

Pongrác, B., Šimek, M., Člupek, M., Babický, V., Lukeš, P., 2018. Spectroscopic characteristics of H $\alpha$ /O I 
atomic lines generated by nanosecond pulsed corona-like discharge in deionized water. J. Phys. D. Appl. Phys. 51, 124001. https://doi.org/10.1088/1361-6463/aaabb1

Prajitno, D.H., Maulana, A., Syarif, D.G., 2016. Effect of Surface Roughness on Contact Angle Measurement of Nanofluid on Surface of Stainless Steel 304 by Sessile Drop Method. J. Phys. Conf. Ser. 739. https://doi.org/10.1088/1742-6596/739/1/012029

Rehman, F., Medley, G.J.D., Bandulasena, H.C.H., Zimmerman, W.B., 2015. Fluidic oscillator-mediated microbubble generation to provide cost effective mass transfer and mixing efficiency to the wastewater treatment plants. Environ. Res. 137, 32-39. https://doi.org/10.1016/j.envres.2014.11.017

Rumbach, P., Go, D.B., 2017. Perspectives on Plasmas in Contact with Liquids for Chemical Processing and Materials Synthesis. Top. Catal. 0, 0. https://doi.org/10.1007/s11244-017-0745-9

Sakiyama, Y., Graves, D.B., Chang, H.-W., Shimizu, T., Morfill, G.E., 2012. Plasma chemistry model of surface microdischarge in humid air and dynamics of reactive neutral species. J. Phys. D. Appl. Phys. 45, 425201. https://doi.org/10.1088/0022-3727/45/42/425201

Sander, R., 1999. Compilation of Henry’s Law Constants for Inorganic and Organic Species of Potential Importance in Environmental Chemistry.

Schwartz, A.J., Cheung, Y., Jevtic, J., Pikelja, V., Menon, A., Ray, S.J., Hieftje, G.M., 2016. New inductively coupled plasma for atomic spectrometry: the microwave-sustained, inductively coupled, atmospheric-pressure plasma (MICAP). J. Anal. At. Spectrom. 31, 440-449. https://doi.org/10.1039/C5JA00418G

Seri, P., Wright, A., Shaw, A., Iza, F., Bandulasena, H., Borghi, C.A., Neretti, G., 2019. Influence of the voltage waveform's shape and on-time duration on the dissolved ozone produced by a DBD bubble reactor. Plasma Sources Sci. Technol.

Shaw, A., Shama, G., Iza, F., 2015. Emerging applications of low temperature gas plasmas in the food industry. Biointerphases 10, 029402. https://doi.org/10.1116/1.4914029

Sigeneger, F., Becker, M.M., Foest, R., Loffhagen, D., 2016. Modelling of plasma generation and thin film deposition by a non-thermal plasma jet at atmospheric pressure. J. Phys. D. Appl. Phys. 49. https://doi.org/10.1088/0022-3727/49/34/345202 
Sivachandiran, L., Khacef, A., 2017. Enhanced seed germination and plant growth by atmospheric pressure cold air plasma: combined effect of seed and water treatment. RSC Adv. 7, 1822-1832. https://doi.org/10.1039/C6RA24762H

Taglioli, M., Shaw, A., Wright, A., FitzPatrick, B., Neretti, G., Seri, P., Borghi, C. a, Iza, F., 2016. EHD-driven mass transport enhancement in surface dielectric barrier discharges. Plasma Sources Sci. Technol. 25, 06LT01. https://doi.org/10.1088/0963-0252/25/6/06LT01

Tian, W., Kushner, M.J., 2014. Atmospheric pressure dielectric barrier discharges interacting with liquid covered tissue. J. Phys. D. Appl. Phys. 47, 165201. https://doi.org/10.1088/0022-3727/47/16/165201

Vasko, C.A., Liu, D.X., Van Veldhuizen, E.M., Iza, F., Bruggeman, P.J., 2014. Hydrogen peroxide production in an atmospheric pressure RF glow discharge: Comparison of models and experiments. Plasma Chem. Plasma Process. 34, 1081-1099. https://doi.org/10.1007/s11090-014-9559-8

Von Gunten, U., 2003. Ozonation of drinking water: Part I. Oxidation kinetics and product formation. Water Res. 37, 1443-1467. https://doi.org/10.1016/S0043-1354(02)00457-8

Wei, C., Zhang, F., Hu, Y., Feng, C., Wu, H., 2017. Ozonation in water treatment: The generation, basic properties of ozone and its practical application. Rev. Chem. Eng. 33, 49-89. https://doi.org/10.1515/revce-2016-0008

Worden, R.M., Bredwell, M.D., 1998. Mass-transfer properties of microbubbles. 2. Analysis using a dynamic model. Biotechnol. Prog. 14, 39-46. https://doi.org/10.1021/bp970131c

Wright, A., Bandulasena, H., Ibenegbu, C., Leak, D., Holmes, T., Zimmerman, W., Shaw, A., Iza, F., 2018. Dielectric barrier discharge plasma microbubble reactor for pretreatment of lignocellulosic biomass. AIChE J. 64, 3803-3816. https://doi.org/10.1002/aic.16212

Ying, K., Al-mashhadani, M.K.H., Hanotu, J.O., Gilmour, D.J., Zimmerman, W.B., 2013a. Enhanced Mass Transfer in Microbubble Driven Airlift Bioreactor for Microalgal Culture. Engineering 2013, 735-743. https://doi.org/10.4236/eng.2013.59088

Ying, K., Gilmour, D.J., Shi, Y., Zimmerman, W.B., 2013b. Growth Enhancement of Dunaliella salina by Microbubble Induced Airlift Loop Bioreactor (ALB)—The Relation between Mass Transfer and Growth Rate. J. Biomater. Nanobiotechnol. 04, 1-9. https://doi.org/10.4236/jbnb.2013.42A001 
Zheng, T., Wang, Q., Zhang, T., Shi, Z., Tian, Y., Shi, S., Smale, N., Wang, J., 2015. Microbubble enhanced ozonation process for advanced treatment of wastewater produced in acrylic fiber manufacturing industry. J. Hazard. Mater. 287, 412-420. https://doi.org/10.1016/j.jhazmat.2015.01.069

Zhou, R., Zhou, R., Zhang, X., Zhuang, J., Yang, S., Bazaka, K., (Ken) Ostrikov, K., 2016. Effects of Atmospheric-Pressure N2, He, Air, and O2 Microplasmas on Mung Bean Seed Germination and Seedling Growth. Sci. Rep. 6, 32603. https://doi.org/10.1038/srep32603

Zimmerman, W.B., Tesař, V., Bandulasena, H.C.H., 2011. Towards energy efficient nanobubble generation with fluidic oscillation. Curr. Opin. Colloid Interface Sci. 16, 350-356. https://doi.org/10.1016/j.cocis.2011.01.010 